$R R-75-24$

SPATIAL POPULATION DYNAMICS

Andrei Rogers

Frans Willekens

July 1975

Research Reports are publications reporting on the work of the authors. Any views or conclusions are those of the authors, and do not necessarily reflect those of IIASA. 
SPATIAL POPULATION DYNAMICS

TABLE OF CONTENTS

1. Introduction . . . . . . . . . . . . . . . . . . . . . 1

2. The Components of Multiregional Population Growth . . . . . . . . . 3

2.1 Fertility . . . . . . . . . . . . . . . . . . 5

2.2 Mortality ......................... 7

2.3 Migration . . . . . . . . . . . . . . . . . 9

2.4 Regional Age Compositions and Regional Shares . . . . . . . . . . 12

3. The Spatial Dynamics of Stable Populations . . . . . . . . . . . . . 14

3.1 Characteristics of Stable Multiregional Populations . . . . . . 16

3.2 Two Families of Model Stable Multiregional Populations . . . . 23

3.3 Spatial Impacts of Changes in the Components of Multiregional Population Growth.............. . 28

4. The Spatial Dynamics of Stationary Populations . . . . . . . . . 32

4.1 Characteristics of Stationary Multiregional Populations . . . . . 34

4.2 Alternative Spatial Paths to a Stationary Multiregional

Population . . . . . . . . . . . . . . . . . . . . . . . 37

4.3 On the Momentum of Multiregional Population Growth . . . . . . 42

5. Conclusion . . . . . . . . . . . . . . . . . . . . 46 


\section{SPATIAL POPULATION DYNAMICS ${ }^{*}$}

Andrei Rogers and Frans Willekens ${ }^{* *}$

\section{Introduction}

The evolution of every regional human population is governed by the interaction of births, deaths, and migration. Individuals are born into a population, age with the passage of time, reproduce, and ultimately leave the population because of death or outmigration. These events and flows enter into an accounting relationship in which the growth of a regional population is determined by the combined effects of natural increase (births minus deaths) and net migration (inmigrants minus outmigrants). This paper focuses of such relationships and seeks to identify and clarify some of the more fundamental population dynamics that are involved.

In considering how fertility, mortality, and migration combine to determine the growth, age composition, and spatial distribution of a multiregional population, we address several theoretical and empirical issues already studied by Ansley Coale (1972a) in his recent book: The Growth and Structure of Human Populations. But Coale restricts his attention to the evolution of populations that are "closed" to migration, i.e., populations that are undisturbed by in- or outmigration. Since his focus is primarily on national populations, such an assumption does not seriously weaken the significance of his principal conclusions. Regional scientists, however, are generally confronted by problems involving regional populations that are very "open" to migration. Hence they cannot successfully apply the received body of theory of classical single-region mathematical demography. This paper seeks to help remedy that situation by generalizing some of Coale's results to multiregional population systems.

\footnotetext{
*Prepared for presentation at the Fifteenth European Congress of the Regional Science Association, August 26-29, 1975, Budapest, Hungary.

$*+$

The authors are grateful for the data processing and computer programing assistance provided by Luis Castro, Jacques Ledent, and Richard Walz. The figures were drawn by Luis Castro.
} 
We proceed in three stages. First, we consider several well-defined regularities that are exhibited by the fertility, mortality, and migration schedules of human populations. Next, we study some of the principal population dynamics that connect such schedules with the growth, age composition, and spatial distribution of multiregional populations that are subjected to them. Finally, we examine some of the spatial implications of zero population growth. 


\section{The Components of Multiregional Population Growth}

The proportional allocation of a multiregional population among its constituent regions and the age compositions of its regional populations are determined by the recent history of fertility, mortality, and internal migration to which it has been subject. At any given moment its crude regional rates of birth, death, migration, and growth are all governed by the interaction of its regional age compositions and regional shares with the prevailing regime of growth that is defined by the current regional age-specific schedules of fertility, mortality, and migration. Knowledge of surh schedules for a sufficiently long past period of time enables one to obtain current regional age compositions, regional shares, and regional component rates, inasmuch as the influence of a past population distribution on the current one declines over time and ultimately disappears entirely (Coale, 1972a, Lopez, 1961). If the regime of growth is held fixed for a long enough period of time, then as we shall show in section 3 , the population evolves into a stable population with fixed regional age compositions and regional shares and a constant annual rate of growth.

Consider a regional female population for which the annual regional rates of fertility, mortality, and migration at age $x$ and time $t$ are denoted by $m_{j}(x, t)$, $\mu_{j}(x, t)$, and $v_{j k}(x, t)$, respectively. If $c_{j}(x, t)$ is the population's age composition and $\operatorname{SHA}_{j}(t)$ is its regional share of the total multiregional population, Lhen, denoting the 1 ast age of 1 ife by $w$, we may define 


$$
\begin{aligned}
b_{j}(t) & =\int_{0}^{\omega} c_{j}(x, t) m_{j}(x, t) d x \\
d_{j}(t) & =\int_{0}^{\omega} c_{j}(x, t) \mu_{j}(x, t) d x \\
o_{j}(t)=\sum_{k=1}^{m} o_{j k}(t) & =\sum_{k=1}^{m} \int_{k \neq j}^{w} c_{j}(x, t) v_{j k}(x, t) d x \\
i_{j}(t)=\sum_{k=1}^{m} i_{k j}(t) & =\sum_{k=1}^{m} \frac{\operatorname{sHA}_{k}(t)}{\operatorname{sHA}_{j}(t)} o_{k j}(t) \\
r(t) & =b_{j}(t)-d_{j}(t)-o_{j}(t)+i_{j}(t)
\end{aligned}
$$

to be its annual crude rates of birth, death, outmigration, inmigration, and growth, respectively.

We begin this section of our paper by identifying several regularities in the age schedules of the components of multiregional population growth. The variations with age that are exhibited by such schedules are summarized and subsequently used to develop an improved understanding of how changing levels and patterns of fertility mortality, and migration influence the evolution of particular regional age conpositions and regional shares in a multiregional population. 


\subsection{Fertility}

Age-specific rates of childbearing in human populations are shaped by both biological and social factors. The capacity to bear children generally begins at an age $\alpha$ of about 15 and ends by age $\beta$ which is normally close to 50 . In between these ages tìe fertility surve is unimodal, attaining its peak somewhere betweer ages 20 and 35 . The precise form of this curve depends on a number of social variables, among which age at marriage and the degree of contraception practiced are of paramount importance.

Figure 2.1A illustrates several fertility schedules which exhibit a general pattern that persists across a wide variety of regional populations. In all, childbearing begins early in the teenage years, rises to a peak in the twenties or thirties, and then declines regularly to zero by age 50. A useful summary measure of this pattern is the mean age of the schedule

$$
\overline{\mathrm{m}}=\frac{\int_{\alpha}^{\beta} \mathrm{xm}(\mathrm{x}) \mathrm{dx}}{\int_{\alpha}^{\beta} \mathrm{m}(\mathrm{x}) \mathrm{dx}}
$$

The level of fertility is given by the area under the curve, which is called the total fertility rate (TFR) if the schedule refers to live births of both sexes and the gross reproduction rate (GRR) if to female births alone. This level may be interpreted as the number of children an average woman would have if the particular fertility schedule prevailed during her lifetime.

After a study of the relative age patterns of age-specific fertility rates in 52 countries with different levels of fertility, Rele (1967) concludes that they follow, on average, the ratio $1: 7: 7: 6: 4: 1$ for the six quinquennial reproductive age groups between ages 15 to 44. Coale and Demeny (1966) go a step further and distinguish between 4 such patterns to sumarize a similar collection of published national age-specific birth rates by means of four basic fertility schedules, each 
O
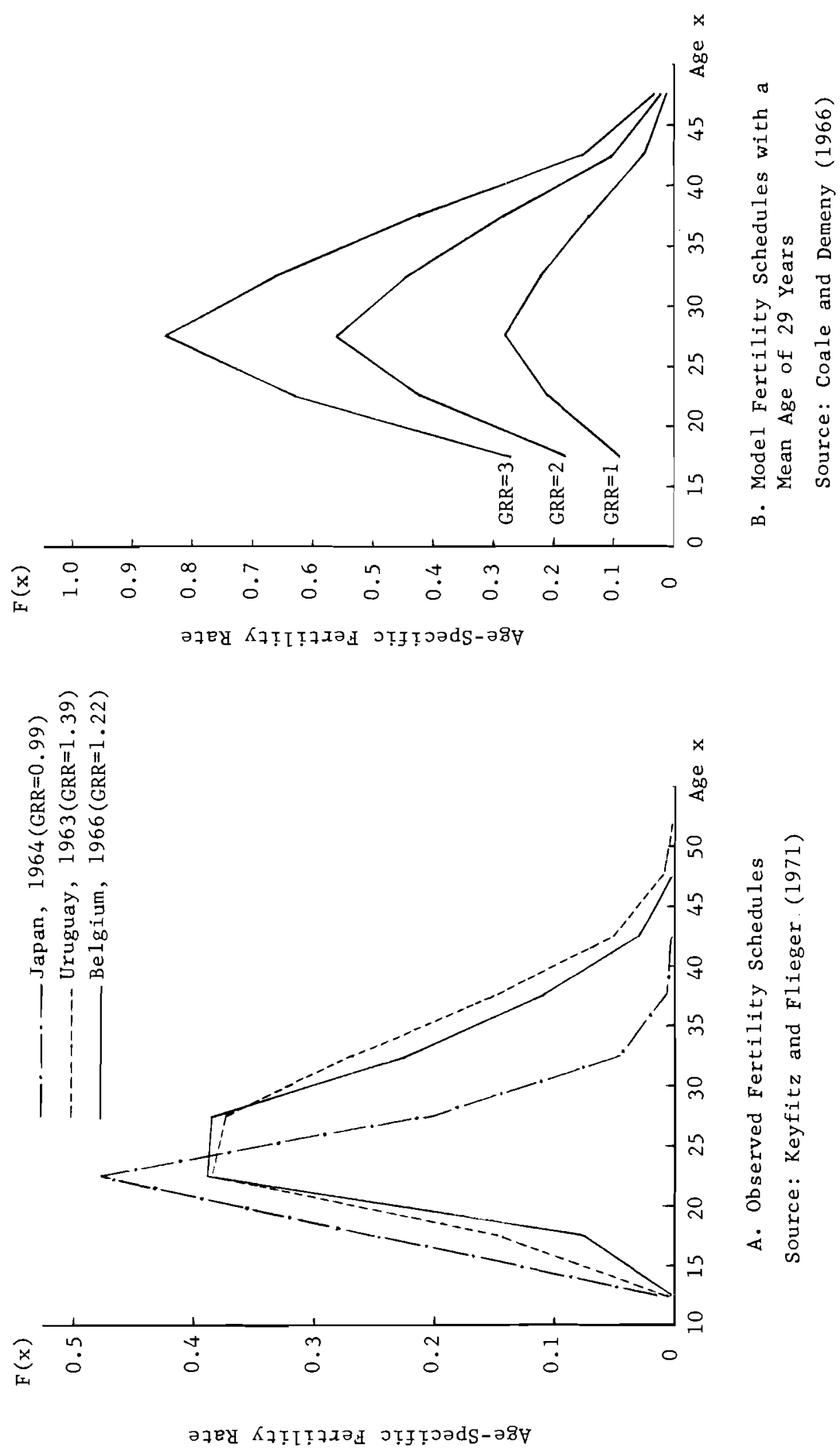
of which is scaled to a GRR of unity and associated with a particular mean age m. Figure 2.1B shows the curves of their fertility schedule with a mean age of 29 as its level is increased from a GRR of unity to a GRR of 3. 


\subsection{Mortality}

Observed age-specific death rates of both high and low mortality populations exhibit a remarkably regular pattern. They normally show a moderately high mortality immediately after birth, after which they drop to a minimum between ages 10 to 15, then increase slowly until about age 50, and thereafter rise at an increasing rate until the last years of life. Moreover, in each mortality schedule the death rates experienced at different ages are highly intercorrelated, because if health conditions, for example, are good or poor for one age group in a population they also will tend to be good or poor for all other age groups in that population. Hence if mortality at a particular age in one schedule exceeds that of the same age in another, the first is likely to also have higher death rates at every other age as well. Because of this property, demographers normally do not find it necessary to use an index such as the mean age of the mortality schedule in order to differentiate patterns of mortality (although they may group schedules into separate "families"). Generally only the level of a mortality schedule is defined by specifying its implicit expectation of life at birth e(o), and it is assumed that the age pattern of the schedule follows that found in most observed curves of mortality.

Figure 2.2A presents several observed schedules of mortality which illustrate the normal age pattern. Mortality is high during infancy, ranging anywhere from 18 to 60 per thousand live births; it is low between ages 10 through 15 , falling to a value in the range of 0.28 to 0.42 per thousand; it then rises, gradually at first and more sharply after the late fifties, to values that in the late sixties lie between 20 to 30 per thousand.

After an extensive study of national populations, Coale and Demeny (1966) conclude that four families of mortality schedules adequately embrace the principal variations in age patterns which they discovered: 


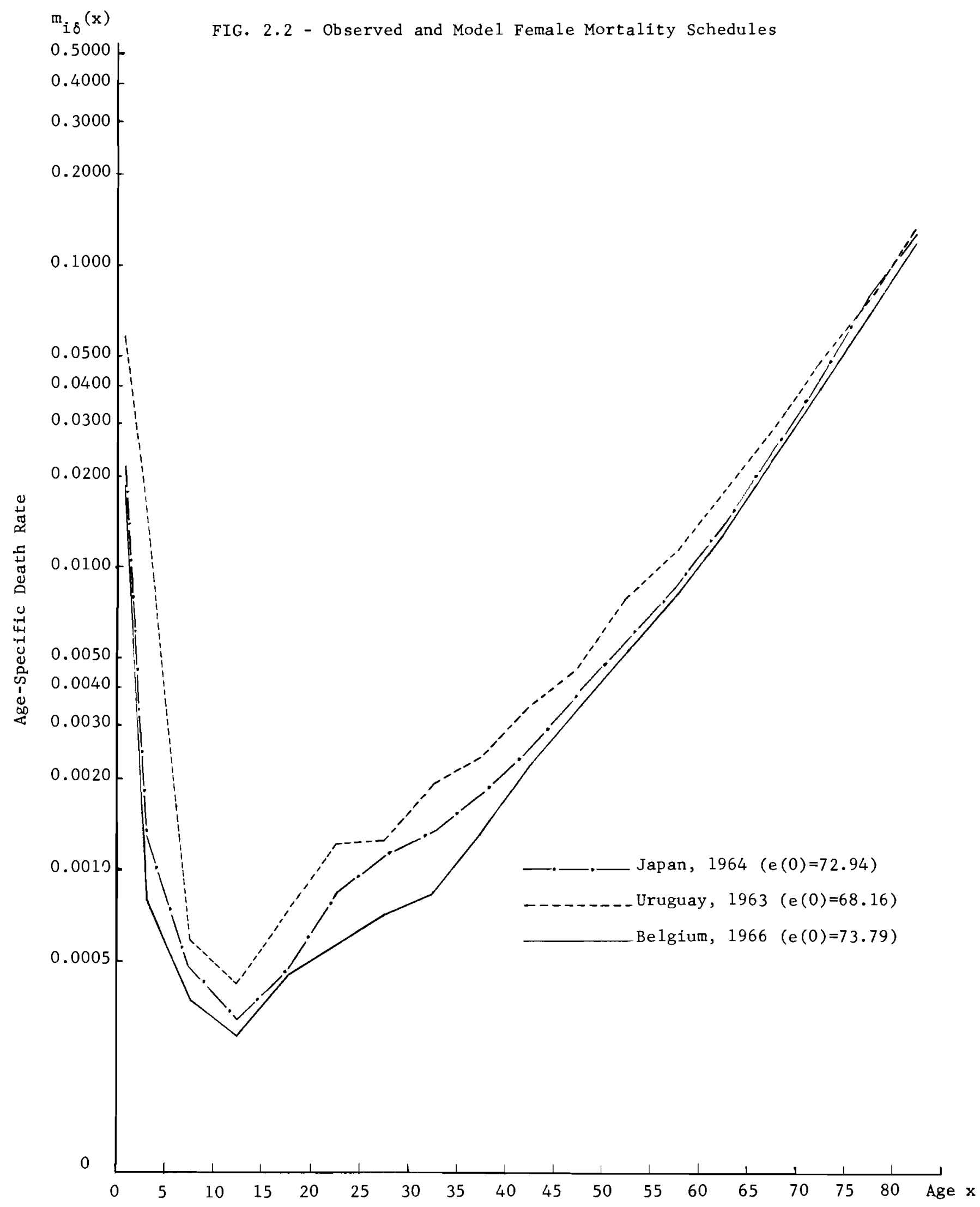

A. Observed Mortality Schedules

Source: Keyfitz and Flieger (1971) 


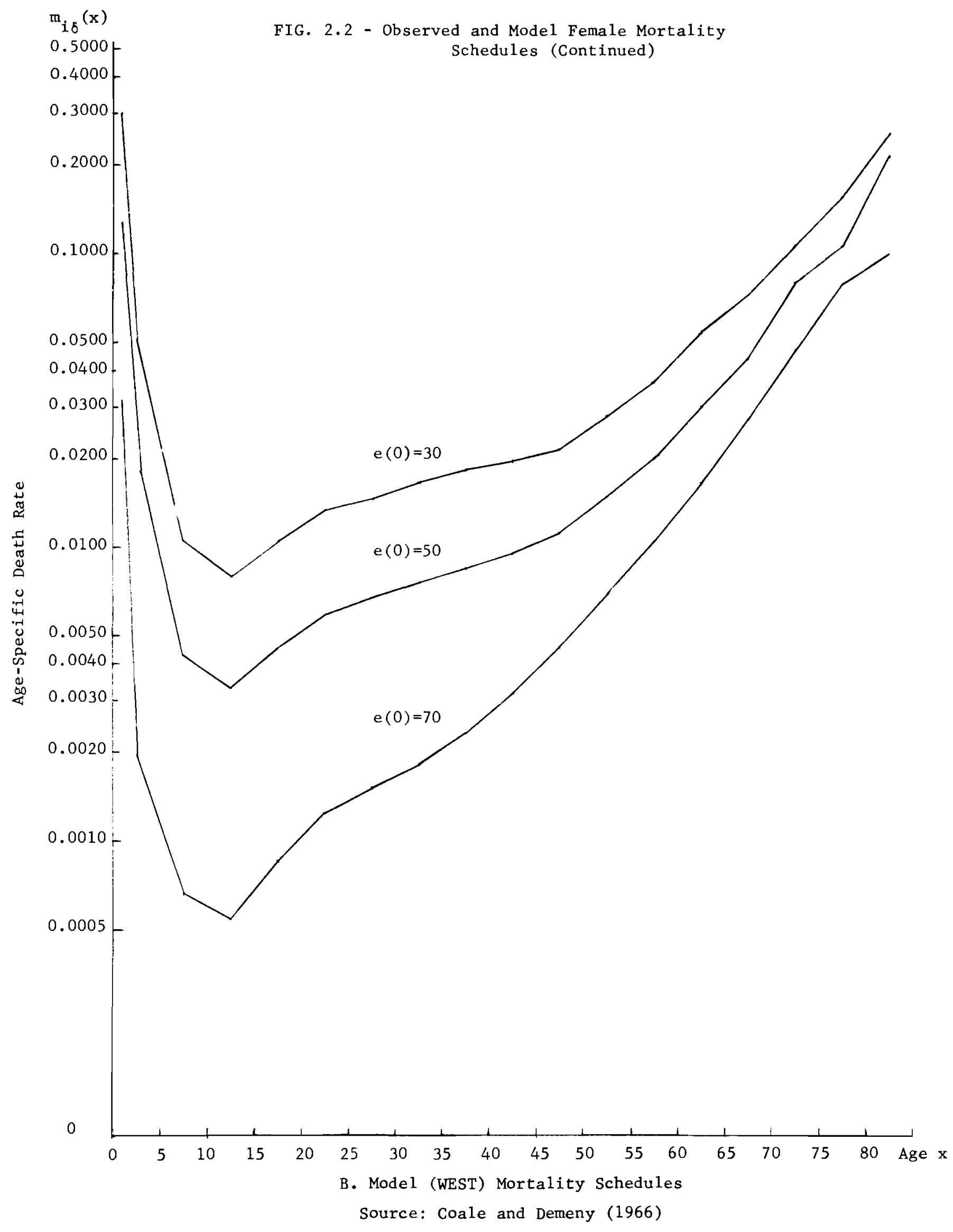


"One of these age patterns characterizes the mortality experienced in Norway, Sweden, and Iceland; another the mortality schedules of central and parts of eastern Europe; a third the schedules of Spain, Portugal, and southern Italy; and a fourth encompasses mortality in western Europe, northern America, Oceania, Japan, and Taiwan," (Coale, 1972a, p. 9).

They designate these four families by the labels NORTH, EAST, SOUTH, and WEST, respectively, and go on to calculate 24 "model" life tables for each of these age patterns of mortality at levels of mortality ranging from a life expectancy of 20 years to one of 77.5 . Figure 2.2B illustrates several typical mortality schedules drawn from their WEST family. 


\subsection{Migration}

As in the case of mortality, migration rates among the different age and sex groups of a population are highly intercorrelated, with high (or low) migration rates among one segment of the population implying high (or low) migration rates for other segnents of the same population. This association occurs because migration often is a response to changing economic conditions, and if these are good or poor for one segment of a population, they also are likely to be good or poor for other segments as well.

Demographers have long recognized the strong regularities that persist anong age-specific schedules of migration, the most prominent being the high concentration of migration among young adults (e.g., Long, 1973; Lowry, 1966). Rates of migration are also high among children, starting with a peak during the first year of life and dropping to a low point at about age 16. Beyond that age the curve turns sharply upward to another peak near age 22, declining regularly thereafter except for a slight hump around 62 through 65, the principal ages of retirement.

The empirical regularities are not surprising. Young adults exhibit the highest migration rates because they are much less constrained by ties to their comnunity. They are more likely to be renters than home owners, their children generally are not yet in school, and job seniority is not an important consideration. Since children normally move only as members of a family, their migration pattern mirrors that of their parents. Inasmuch as younger children generally have younger parents, the migration rates of infants are higher than those of adolescents. Finally, the small hump in the age profile between ages 62 to 65 describes inigration after retirement and usually reflects moves made to more sunnier and milder climates.

Figure 2.3A repeats the fundamental age pattern of migration described above but expresses it in terms of 5 -year age intervals. In consequence, the low rate of migration at age 16 is aggregated with the substantially higher rates that 


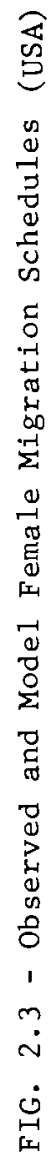

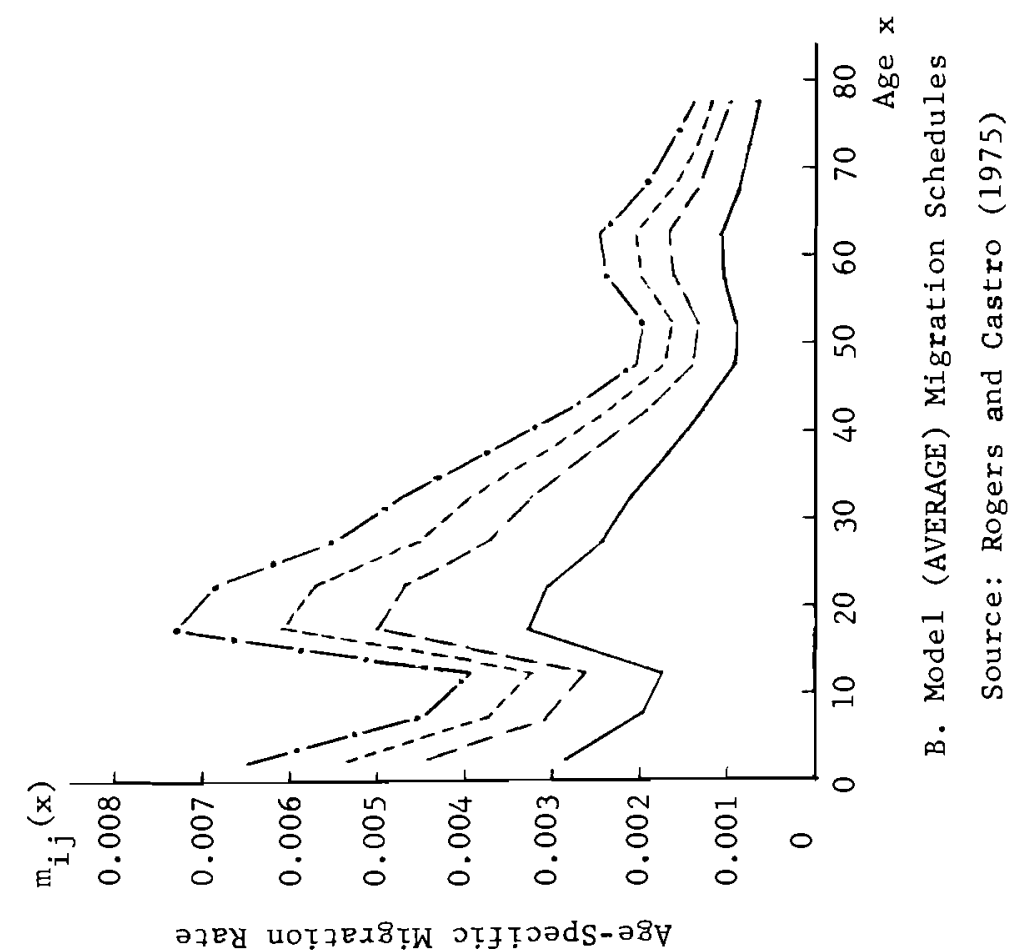

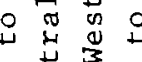

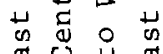

đ广

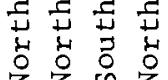

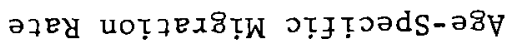
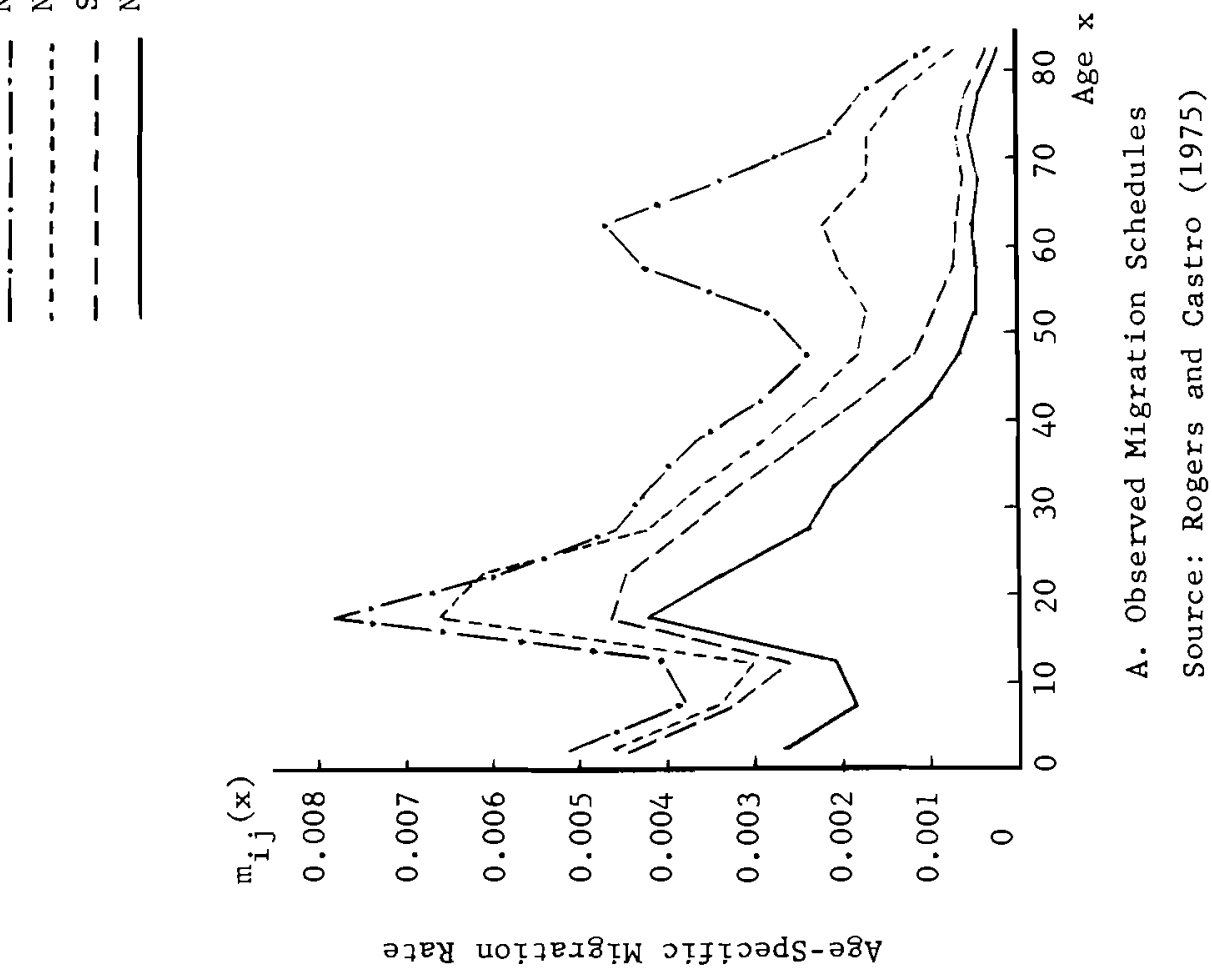
follow it, thereby shifting the low point among teenagers to a younger age. An analogous shift occurs with respect to the principal peak. The overall profile, however, remains essentially unchanged, with peaks occurring at infancy, during the young adult ages, and at retirement. Variations in the location of the principal peak and in the levels of migration to major retirement areas indicate that as in the case of mortality, age patterns of migration may usefully be disaggregated into families which are distinguished by the location and relative height of their peaks. Alternatively, such a disaggregation may be carried out, in the manner of fertility schedules, by means of the mean age of migration

$$
\bar{n}_{i j}=\frac{0^{\omega} x v_{i j}(x) d x}{\int_{0}^{\omega} v_{i j}(x) d x},
$$

which readily may be used to classify migration schedules into "young" and "old" categories, perhaps with suitable gradations in between.

Two alternative ways of formally specifying the level of migration from one region to another are immediately suggested by our discussion of fertility and mortality schedules. The first adopts the fertility point of view and defines the migration level from region $i$ to region $j$ in terms of the area under the relevant migration schedule, designating it the gross migra-production rate, $G_{i j}$ say. The second adopts a mortality perspective and defines the same migration level in terms of the fraction of an average person's lifetime that is spent in the region of destination. Specifically,

$$
i_{j}=\frac{i_{j}^{e}(0)}{i^{e(0)}}
$$

is said to be the migration level with respect to region $j$ of individuals born 
in region $i$. The numerator in the fraction represents the number of years expected to be lived in region $j$, on the average, by individuals born in region $i$ and having a total life expectancy of $i(0)$ years. We adopt the latter perspective in this paper and in Figure 2.3B demonstrate its application by illustrating several typical model migration schedules. These are developed in another paper, which also deals with the important problem of disaggregating such schedules into families containing "young" and "old" age profiles (Rogers and Castro, 1975). 


\subsection{Regional Age Cononsitions and Regional Shares}

The equations in (2.1) show how regional age compositions and regional shares together with age schedules of fertility, murtality, and migration determine the principal regional component rates of multiregional population growth and change. A single set of such age schedules can produce quite different crude regional rates of birth, death, and migration if combined with differing sets of regional age compositions and regional shares. Consequently such rates may be unsatisfactory summary measures of the components of multiregional population growth.

By way of illustration, consider the empirical age compositions set out in Figure 2.4A. Belgium had lower mortality rates at every age in 1966 than did Uruguay in 1963 , but it had a higher crude death rate (12.14>11.28). Japan, on the other hand, had lower fertility rates in 1964 than Belgium at every age save one, but it exhibited a higher crude birth rate $(17.71>15.86)$. In each case, the cause of the apparent anomaly was the difference in the age compositions of the populations compared. Belgium had a much larger proportion of its population over 65 than did Uruguay. Japan had a substantially larger proportion of its population in the childbearing ages than did Belgium. Because these differences in age composition occurred at ages where the respective rates in the relevant schedule were high or low, changes in the age composition biased the values of the consolidated rates in the expected directions.

Changes in regional shares have an analogous but somewhat different way of helping to shape regional component rates. Regional shares serve as weights in the consolidation process. Hence the same outmigration rate originating from a region that is twice the size of another will develop twice the impact on the size of the population in the destination region. Moreover, since any idiosyncracies in the age profile of a sending region's migration schedule are transmitted to the receiving region's population, large sources of heavy outmigration can have 


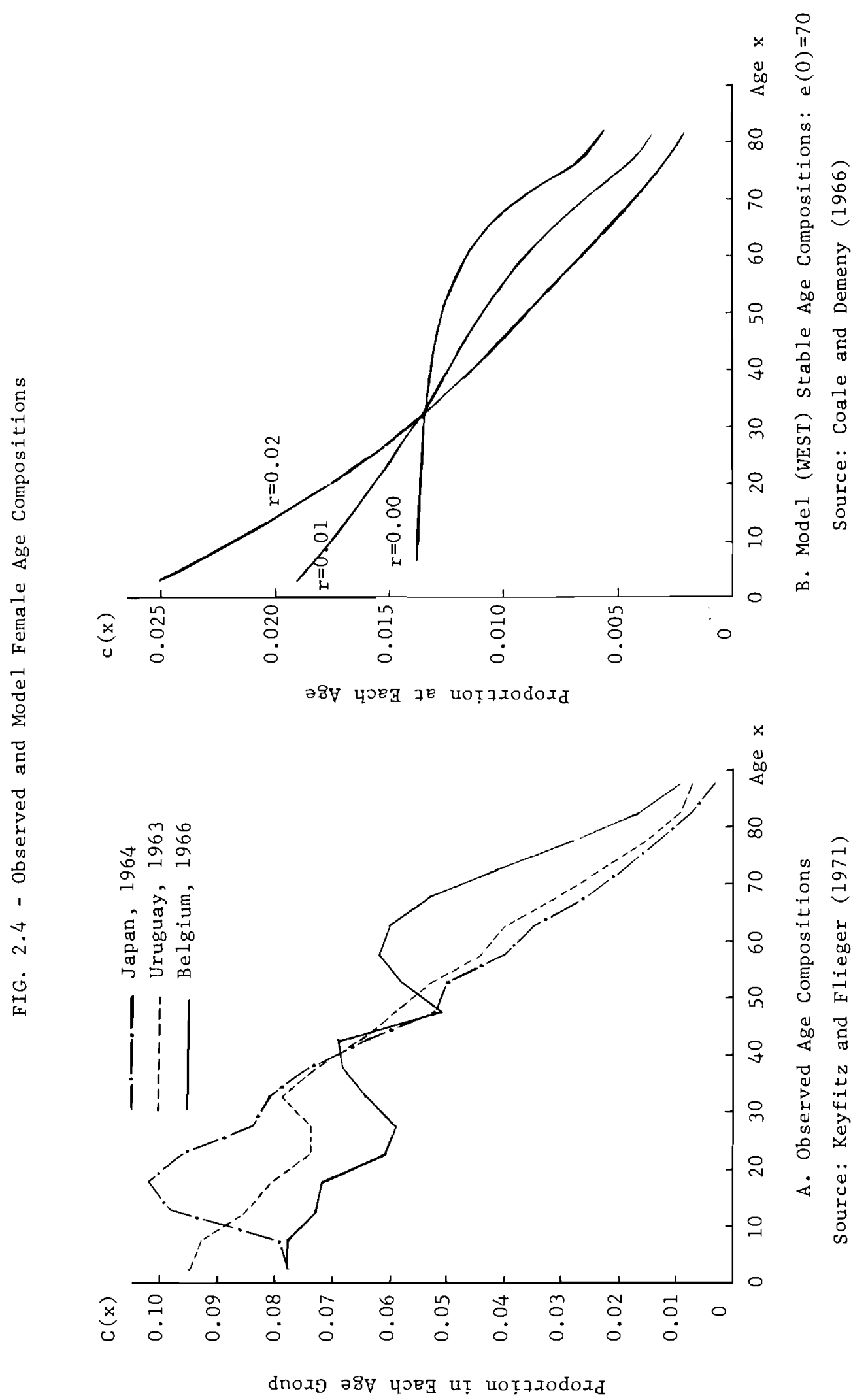




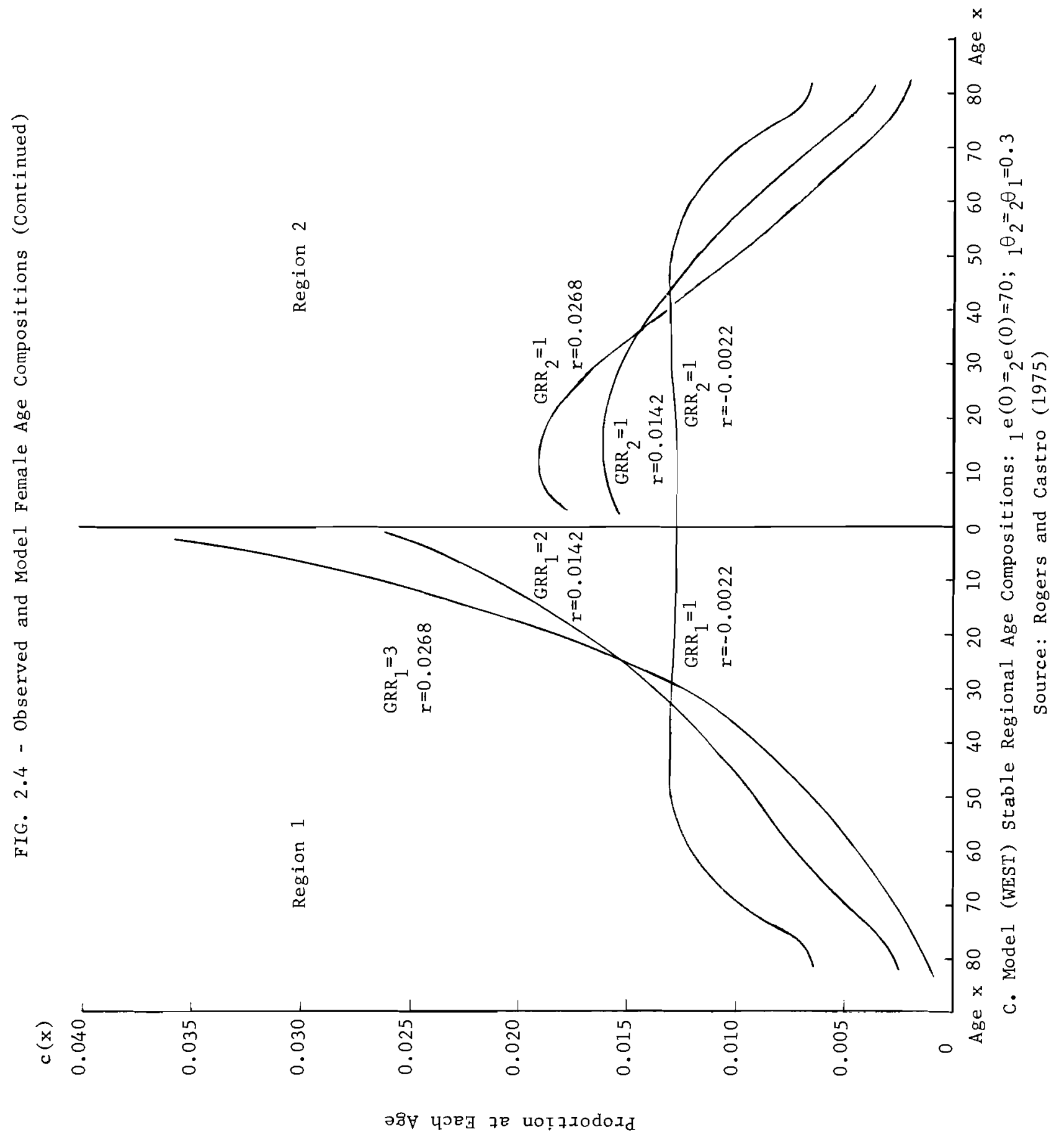


substantial impact on the values assumed by all of the component rates in i destination region.

Finally, while it is important to underscore the powerful influence that regional age compositions and regional shares have in shaping rogional conponent rates, one must also recognize that past records of fertility, mortality, aind migration play an equally important role in the deternination of present regional age compositions and shares, inasmuch as the latter arise out of a history of regional births, deaths, and internal migration. For example, a region experiencing high levels of fertility will have a relatively younger population, but if it also is the origin of high levels of outmigration a large proportion of its young adults will move to other regions, producing a higher growth rate in the destination regions while lowering the average age of its own population. ${ }^{1}$ This suggests that inferences made about fertility, say, on the basis of a model that ignores migration may be seriously in error. For example, Figure 2.4C illustrates the significant impact on the ultimate stable age composition and regional share of region 2 that is occasioned by a doubling and tripling of fertility levels in region 1 while holding everything else constant. The. mean age of the population in region 2 declines by 5.1 and 8.9 years, respectively, while its regional share decreases by 24 percent in the first instance and by 36 percent in the second. It is to spatial population dynamics of this kind that we now turn in the remainder of this paper.

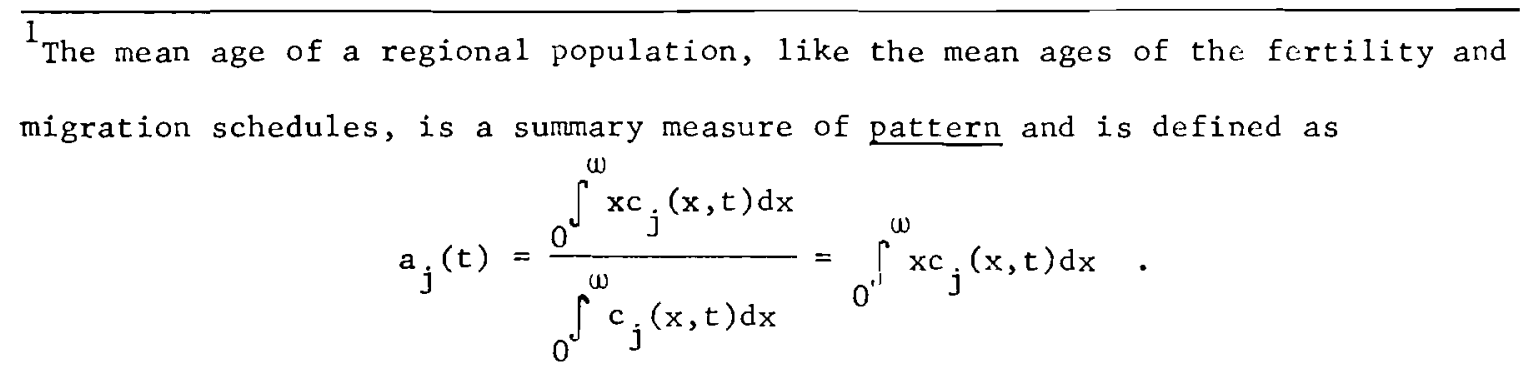
The regional share $\mathrm{SHA}_{j}(t)$, on the other hand, is a summary measure of level. 
3. The Spatial Dynamics of Stable Populations

The regional age compositions and regional shares of a closed multiregional population are completely determined by that population's recent history of fertility, mortality, and internal migration. A particularly useful way of understanding the evolution of such age compositions and shares is to imagine them as describing a population which has been subjected to fertility, mortality, and migration schedules that have remained unchanged for a long period of time, say a century. The population that develops under such circumstances is said to have been subjected to a fixed regime of growth and is called a stable multiregional population. Its principal characteristics are: unchanging regional age compositions and regional shares; constant regional annual rates of birth, death, and migration; and a fixed multiregional annual rate of growth that also is the annual rate of population increase in each and every region.

A frequently raised objection to the use of stable population theory is the implausibility of the assumption of an unchanging regime of growth. Such an objection confuses projection with prediction. No one truly believes that fertility, mortality, and migration schedules will remain unchanged for a prolonged period of time; yet our understanding of current demographic rates can be substantially enhanced by a projection of their long-run consequences. Keyfitz (1972, p. 347) has likened such projections to "microscopic examinations" because they magnify the effects of differences in current rates in order to more easily identify their true meaning. Others have called them "speedometer readings" to emphasize their monitoring function and hypothetical nature (Coale, 1972a, p. 52; Rogers, 1971, p. 426). But perhaps the most vivid interpretation of the role of infinite horizon projections was offered by Gale $(1967$, p. 2) in the context of economic 
"To describe the situation figuratively, one is guiding a ship on a long journey by keeping it lined up with a point on the horizon even though one knows that long before that point is reached the weather will change (out in an unpredictable way) and it will be necessary to pick up a new course with a new reference point, again on the horizon rather than just a short distance ahead."

In this section of our paper we examine the stable multiregional populations that evolve out of particular histories of fertility, mortality, and internal migration. By tracing through the ultimate consequences of alternative fixed regimes of growth, we strive for a further understanding of the spatial dynamics of the hypothetical populations that they describe. 


\subsection{Charactoristics of Stible Multirasond Populations}

Imagine a multiregional female pupulation that has been exposed to a fixed regime of growth for a very long period of time. ${ }^{1}$ The number of women aged $x$ to $x+d x$ in this population at time $t$ are survivors of those born $x$ years ago, $x \leq t$, and therefore may be denoted by $\underset{\sim}{p}(x)\{\underset{\sim}{g}(t-x)\} d x$, where $\underset{\sim}{p}(x)$ is a matrix of regional probabilities of surviving to age $x$ and $\{\underset{\sim}{B}(t)\}$ is a vector of regional births at time $t$. If subjected to a regine of fertility described by $\underset{\sim}{\mathbb{N}}(x)$, a diagonal matrix of age-specific annual rates of childbearing at age $x$, these women at time $t$ give birth to $\underset{\sim}{M}(x) \underset{\sim}{P}(x)\{\underset{\sim}{g}(t-x)\} d x$ baby girls per year. Integrating over all ages $x$, we obtain the multiregional Lotka renewal equation

$$
\{\underset{\sim}{B}(t)\}=\int_{0}^{t} \underset{\sim}{M}(x) \underset{\sim}{P}(x)\{\underset{\sim}{B}(t-x)\} d x=\int_{0}^{t} \Phi(x)\{\underset{\sim}{B}(t-x)\} d x \text {, for } t \geq \beta,
$$

where $\beta$ denotes the last age of childbearing and $\Phi(x)$ is the multiregional net maternity function. 2

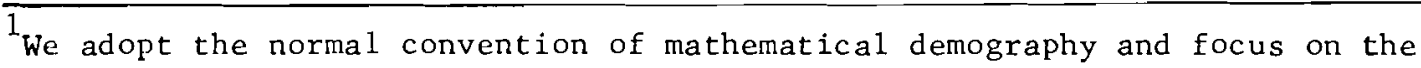
female population. It should be clear, however, that our arguments apply to any single-sex population: male, female, or total.

${ }^{2}$ Contrary to conventional matrix notation, we use a transposed ordering of subscripts so as to preserve a left-to-right ordering of successive regions of residence in the usual "matrix-times-a-vector" multiplication projection process of single-region mathematical demography. For example, the probability that a baby girl born in region $j$ will be alive in region $i$ at age $x$ is denoted by ${ }_{j} p_{i}(x)$ and appears as the element in the $i \underline{\text { th }}$ row and $j \underline{\text { th }}$ column of $\underset{\sim}{P}(x)$. The multiplication of the vector of births $\{\underset{\sim}{B}(t-x)\}$ by $\underset{\sim}{P}(x)$ then yields a vector of sums such as $\sum_{j=1}^{m} B_{j}(t-x){ }_{j} p_{i}(x)$, in which the subscript referring to region of birth appears before the one defining the subsequent region of residence at age $x$. Extensions to denote several successive regions of residence, e.g., ${ }_{j}{ }^{p}{ }_{i k}(x)$, are straightforward. 
Following the procedure used in the single-region model (e.g., Keyfitz, 1968, Ch. 5) we observe that the trial solution $\{B(t)\}=\{Q\} e^{\text {rt }}$ satisfies (3.1) provided $r$ takes on a particular value, which we shall derive presently. Substituting the trial solution into (3.1) transforms that equation into the multiregional characteristic equation

$$
\{Q\}=\int_{\alpha}^{\beta} e^{-r x} \underset{\sim}{M}(x) \underset{\sim}{P}(x)\{Q\} d x=\left[\int_{\alpha}^{\beta} e^{-r x} \underset{\sim}{\sim}(x) d x\right]\{\Omega\}=\Psi(r)\{Q\},
$$

where $\underset{\sim}{\Psi}(r)$ is the multiregional characteristic matrix. Note that the range of integration has been narrowed to embrace only the ages of childbearing $\alpha$ through $\beta$.

By moving from (3.1) to (3.2) we have reduced our problem to one of finding the value of the constant $r$ that satisfies the characteristic equation: $\{Q\}=\Psi(r)\{\Omega\}$. Rewriting that equation as

$$
[\Psi(r)-I]\{Q\}=\{0\}
$$

we observe that $\{Q\}$ is the characteristic vector that corresponds to the unit dominant characteristic root of $\underset{\sim}{\Psi}(r)$, and $r$ is the number which gives that matrix such a value for its dominant characteristic root. ${ }^{3}$

The system of equations in (3.3) can have only one maximal real root $r$ and any complex roots that satisfy (3.3) must occur in complex conjugate pairs whose real components are smaller than the maximal real root. Consequently, the birth sequence $\{\underset{\sim}{B}(t)\}=\sum_{h=1}^{\infty}\left\{\beta_{h}\right\} e^{r_{h}{ }^{t}}$ is increasingly dominated by its first term as

\footnotetext{
${ }^{3}$ Such a root is in fact a function which associates each value of $r$ with the dominant characteristic root of $\underset{\sim}{\Psi}(r)$ evaluated at that particular value of $r$. This function is continuous, concave upward thro:gtout, and its valics decrease monotonically as its argument increases. Thus a dominant characteristic root of unity can occur only once, and it will always take on that value when $r$ assumes its maximal value.
} 
t becomes large. Thus, ultimately,

$$
\{\underset{\sim}{B}(t)\} \doteqdot\left\{\Omega_{1}\right\} e^{r_{1} t}=\{\Omega\} e^{r t},
$$

where we omit the unit subscripts for convenience.

Exponentially growing births produce an exponentially growing population, $\{\underset{\sim}{K}(t)\}$ say, which maintains stable regional age compositions and a constant regional allocation of the total multirezional population:

$$
\begin{aligned}
\{\underset{\sim}{K}(t)\} & =\int_{0}^{\omega}\{\underset{\sim}{k}(x, t)\} d x=\int_{0}^{\omega} \underset{\sim}{P}(x)\{\underset{\sim}{B}(t-x)\} d x=\int_{0}^{\omega} e^{r(t-x)} \underset{\sim}{P}(x)\{g\} d x \\
& =e^{r t} \int_{0}^{\omega} e^{-r x} P(x)\{g\} d x=e^{r t} \underset{\sim}{-1}\{g\}=\{\underset{\sim}{\sim}\} e^{r t},
\end{aligned}
$$

where $\{\underset{\sim}{\sim}\}$ is a vector of stable equivalent regional populations (Keyfitz, 1969), and $\underset{\sim}{b}$ is a diagonal matrix of regional intrinsic birth rates

$$
b_{i}=\frac{1}{\int_{0}^{\omega} e^{-r x} \sum_{j=1}^{m} \frac{Q_{j}}{Q_{i}} p_{i}(x) d x} .
$$

A multiregional population that is projected to stability under a constant regime of growth will ultimately increase by the ratio $e^{5 r}$ every 5 years. If this population were stable to begin with and contained $Y_{i}$ individuals in each region, $i=1,2, \ldots, m$, then by time $5 t$ it would have grown to $\{\underset{\sim}{\sim}\} e^{5 r t}$. Thus, as Keyfitz (1969) suggests, the stable equivalent population of an observed population may be found by projecting the latter forward t periods to stable growth and then backward an equal length of time by dividing by $e^{5 \mathrm{rt}}$. The resulting hypothetical population, if increased by the ratio $e^{5 r}$ after every unit time interval of 5 years, would approach the same asymptotic levels as the projected observed population. By analogous reasoning, 


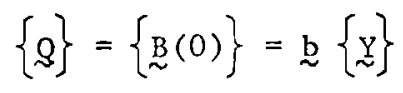

may be referred to as the vector of stable equivalent regional births.

The number of $\mathrm{j}$-born persons at age $\mathrm{x}$ in region $\mathrm{i}$ in a stable multiregional population is equal to the number born $x$ years ago in region $j$ times the proportion of those babies alive $x$ years later in region $i$. Suming this quantity over all regions in the multiregional system and dividing it by the same totai integrated over all ages of life gives the regional age composition

$$
c_{i}(x)=\frac{\sum_{j=1}^{m} Q_{j} e^{-r x}{ }_{j} p_{i}(x)}{\int_{0}^{\omega} \sum_{j=1}^{m} Q_{j} e^{-r x}{ }_{j} P_{i}(x) d x}=b_{i} e^{-r x} \sum_{j=1}^{m} \frac{Q_{j}}{Q_{i}} j_{j} P_{i}(x)
$$

or, in matrix form,

$$
\{c(x)\}=\underset{\sim}{b} \mathrm{e}^{-\mathrm{rx}} g^{-1} \mathcal{L}(\mathrm{x})\{g\}=g^{-1} c(\mathrm{x})\{g\},
$$

where

$$
\underset{\sim}{c}(\mathrm{x})=\underset{\sim}{\mathrm{b}} \mathrm{e}^{-\mathrm{rx}} \underset{\sim}{\mathrm{P}}(\mathrm{x})
$$

and $Q$ is a diagonal matrix with the elements of $\{Q\}$ along j.ts diagonal.

Having found the stable age composition of each regional population we may proceed to develop a number of demographic measures that describe other important characteristics of such stable multiregional populations. First, the mean age of the population in region $j$ is given by

$$
a_{j}=\int_{0}^{w} x c_{j}(x) d x
$$

and its intrinsic rates of birth, death, outmigration, inmigration and net migration are, respectively,

$$
\begin{aligned}
& b_{j}=\int_{0}^{\omega} c_{j}(x) m_{j}(x) d x \\
& d_{j}=\int_{0}^{\omega} c_{j}(x) \mu_{j}(x) d x
\end{aligned}
$$




$$
\begin{aligned}
& o_{j}=\int_{0}^{w} c_{j}(x) \sum_{\substack{i=1 \\
i \neq j}}^{m} v_{j i}(x) d x \\
& i_{j}=r-b_{j}+d_{j}+o_{j} \\
& n_{j}=i_{j}-o_{j}
\end{aligned}
$$

where $\mu_{j}(x)$ is the instantaneous (i.e., compounded momently) annual rate of mortality at age $x$ in region $j$ and $v_{j i}(x)$ is the corresponding rate of migration from region $j$ to region $i$. Two other useful measures are the net migration rate and the net absence rate, respectively:

$$
\begin{aligned}
& n_{j}=i_{j}-o_{j} \text {, and } \\
& \Delta_{j}=b_{j}-r=d_{j}-n_{j} .
\end{aligned}
$$

Finally, the share of the total multiregional population that is allocated to region $\mathbf{j}$ at stability may be defined in terms of stable equivalent populations as

$$
\operatorname{SHA}_{j}=\frac{Y_{j}}{\sum_{i=1}^{M} Y_{i}}
$$

Table 3.1 presents several fundamental characteristics of the stable female United States population that evolves from a projection using the 1968 growth regime. The national territory is divided into two regions: the West region defined by the U.S. Census Bureau and the rest of the United States. ${ }^{4}$ The expectation of 1 ife of women born in the west was found to be ${ }_{1} \mathrm{e}(0)=75.49$ years with ${ }_{1} \mathrm{e}_{2}(0)=23.10$ years of that total (31 percent) expected to be lived in the rest of the United States. Women born in the rest of the United States, on the

\footnotetext{
${ }^{4}$ The West region is comprised of the following 13 states: Alaska, Arizona, California, Colorado, Hawai, Idaho, Montana, Nevada, New Mexico, Oregon, Utah, Washington, and Wyoming.
} 
TABLE 3.1 - RELATIONS UNDER STABILITY: FEMALE POPULATION OF THE UNITED STATES, 1968

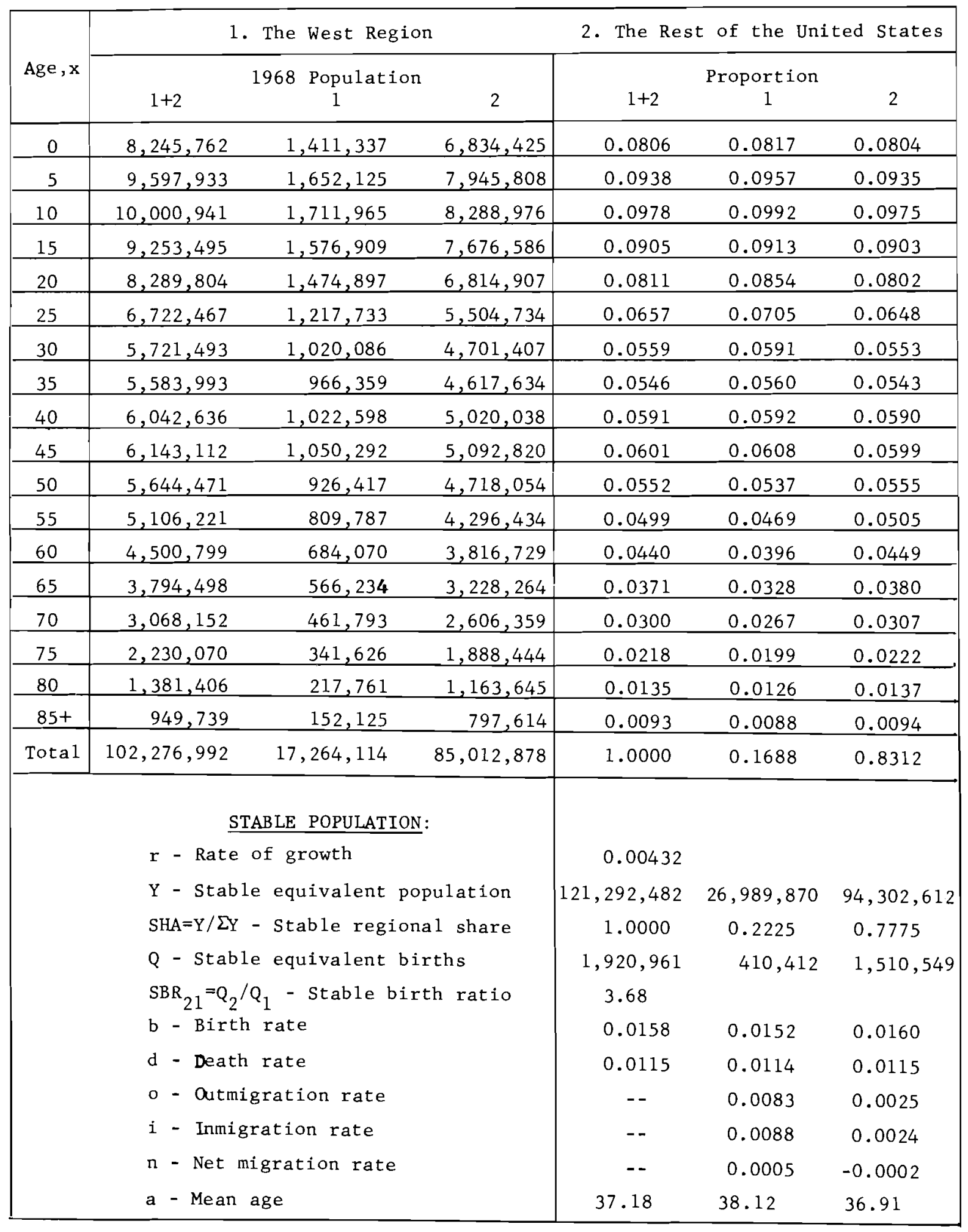


other hand, were expected on the average to live a total of ${ }_{2} \mathrm{e}(0)=74.29$ years with ${ }_{2} e_{1}(0)=6.95$ years of that total ( 9 percent) expected to be lived in the West. Fertility in the West was slightly lower than in the rest of the United States. The former had a gross reproduction rate of 1.13 , whereas the latter experienced a GRR of 1.17. Symbolically,

$$
\underset{\sim}{e(0)}=\left[\begin{array}{rr}
52.39 & 6.95 \\
23.10 & 67.34
\end{array}\right] \quad \underset{\sim}{G R R}=\left[\begin{array}{ll}
1.13 & 0 \\
0 & 1.17
\end{array}\right]
$$

where $\underset{\sim}{\mathrm{e}}(0)=\operatorname{EXP}_{\sim} \cdot \underset{\sim}{\theta}$, and

$$
\operatorname{EXP}_{\sim}=\left[\begin{array}{lr}
75.49 & 0 \\
0 & 74.29
\end{array}\right] \quad \underset{\sim}{\theta}=\left[\begin{array}{ll}
0.69 & 0.09 \\
0.31 & 0.91
\end{array}\right]
$$

The stable projection allocates 22.25 percent of the ultimate national population to the West and accords it an annual growth rate of 4.3 per 1000 , an annual birth rate of 15.2 per 1000 , and a positive annual net migration rate of 0.5 per 1000 . The stable population of the rest of the United States increases at the same intrinsic annual rate of growth, but its other demographic characteristics are quite different. It has a somewhat younger population, a higher annual birth rate, and exhibits a very slight net outmigration to the West. Both regional stable populations are a few years older in mean age than the corresponding observed 1968 populations. 


\subsection{Two Families of Model Stable Multiregional Populations}

The numerical evaluation of the multiregional population growth process described above usually involves a population disaggregated into 18 five-year age groups (0-4 through $85+)$ of which 8 are assumed to be capable of childbearing $(\alpha=10$ through $\beta=50)$. Thus the mathematical representation requires 8 age-specific birth rates, 18 age-specific death rates, and $18(\mathrm{~m}-1)$ age-specific migration rates for each of the m regions comprising the multiregional system. We have seen, however, that among human populations such rates exhibit persistent regularities and therefore are not truly independent observations. In consequence, a remarkably accurate description of spatial population dynamics can be realized with the aid of model stable populations that have been generated using a much smaller number of indices of variation in fertility, mortality, and migration which summarize the kinds of regularities that were identified in section 2.

In their monumental study of single-region model life tables and model stable populations, Coale and Demeny (1966) present two overlapping sets of stable populations which to a large extent provide similar information. Each population is identified by two nonredundant indices of variation relating to fertility and mortality, respectively, and evolves out of a particular combination of a model life table and intrinsic rate of growth or gross reproduction rate. The former are referred to as the "growth rate" stable populations; the latter are called the "GRR" stable populations and rely on a model fertility schedule with a given mean age of childbearing $\bar{m}$, which is assumed to be 29 years. Symbolically, the two sets of model stable populations may be expressed as:

1. Growth Rate Stable Populations : $f(e(0), r)$

2. GRR Stable Populations : $g(e(0)$, GRR)

Model stable multiregional populations may be developed by means of a straightforward extension of the Coale and Demeny method. Underlying every such model population are:(1) a set of regional mortality levels specified by regional 
expectations of life at birth; (2) a set of regional fertility levels defined either by an intrinsic rate of growth and an associated proportional regional allocation of total stable equivalent births, or by a set of regional gross reproduction rates; and, finally, (3) a set of interregional migration levels between every pair of regions in the multiregional system. Symbolically, we may once again express two sets of model stable populations:

1. Growth Rate Stable Multiregional Populations : $f(E \underset{\sim}{\operatorname{X} P}, r, \underset{\sim}{\mathrm{d} R}, \underset{\sim}{\theta})$

2. GRR Stable Multiregional Populations : $g(\underset{\sim}{\operatorname{XxP}}, \underset{\sim}{G R R}, \underset{\sim}{\ominus})$ where $\operatorname{EXP}_{\sim}$ is a diagonal matrix of regional expectations of life at birth ${ }_{i} e(0)$, SBR is a matrix of stable equivalent birth ratios : $S B R{ }_{j i}=Q_{j} / Q_{i} ; \underset{\sim}{\theta}$ is a matrix of migration levels ${ }_{j} \theta_{i}$; and $\underset{\sim}{G R R}$ is a diagonal matrix of regional gross reproduction rates $\mathrm{GRR}_{i}{ }^{5}$

Coale and Demeny observe that growth rate stable populations are more convenient for exploring the implications of various recorded intercensal rates of growth, whereas GRR stable populations are more useful in analyses of the effects of different levels of fertility and mortality. An analogous observation may be made with respect to multiregional populations. Growth rate stable multiregional populations are more convenient for examining the implications of various recorded intercensal rates of growth and regional allocations of total births, whereas GRR stable multiregional populations are more suitable for assessing the impacts of different combinations of regional levels of fertility, mortality, and migration.

Growth rate stable multiregional populations also may be used in connection with analyses of regional allocations of the total multiregional population. 
Expressing the stable regional shares in the form of a diagonal matrix SHA, we easily may establish that

$$
\{\underset{\sim}{b}\}=\operatorname{SHA}_{\sim}^{-1}\left[\sum_{x=0}^{\omega} e^{-r(x+2.5)} L(x)\right]^{-1} \operatorname{SHA}\{1\}
$$

and with it obtain

$$
\mathrm{SBR}=[\mathrm{SHA} \cdot \underset{\sim}{\mathrm{b}}]^{-1} \underset{\sim}{\mathrm{S}}[\mathrm{d} A \cdot \underset{\sim}{\mathrm{b}}],
$$

where $\{\underset{\sim}{b}\}=\underset{\sim}{\sim}\{\underline{\sim}\}$ and $\underset{\sim}{\sim}(x)$ is a matrix comprised of elements ${ }_{j} L_{i}(x)$ that denote the stationary population aged $x$ to $x+4$ years in region $i$ who were born in region $j .6$ Thus we may work with $r$ and either $\underset{\sim}{S B R}$ or SHA. Hence our earlier symbolic expression for growth rate stable multiregional populations has the alternative form

1(b). Growth Rate Stable Multiregional Populations : $h(E \underset{\sim}{P}, \mathbf{r}, \underset{\sim}{\operatorname{SH}}, \underset{\sim}{\Theta})$.

Table 3.2 sets out several specimen model stable multiregional populations which were generated by combining various model schedules of fertility, mortality,

\footnotetext{
${ }^{6}$ The reciprocal of the expectation of life at birth in a single-region life table is equal to the birth rate of the stationary life-table population. Equation (3.9) with $r=0$ may be used to establish the corresponding result for the multiregional life-table population:
}

$$
\{\underset{\sim}{b}\}=\operatorname{SHA}^{-1} \mathrm{\sim}(0)^{-1} \operatorname{SHA}_{\sim}\{\underset{\sim}{1}\}
$$

which, for example, in a two-region model gives

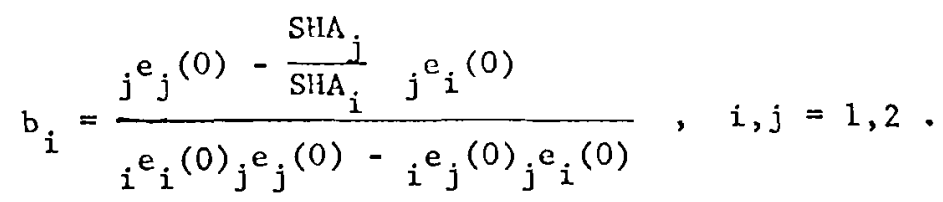

The regional shares in this case refer of course to the regional distribution of the stationary population. 
TABLE 3.2 - MODEL GRR STABLE MULTIREGIONAL (TWO-REGION) FEMALE POPULATIONS WITH EQUAL MORTALITY LEVELS: ${ }_{1} \mathrm{e}(0)={ }_{2} \mathrm{e}(0)=70$

A. Low Fertility in Region 1

\begin{tabular}{|c|c|c|c|c|c|c|c|c|c|}
\hline \multicolumn{10}{|c|}{ Fertility Levels: $\quad \mathrm{GRR}_{1}=1$} \\
\hline & \multicolumn{2}{|r|}{$\mathrm{GRR}_{2}=1$} & & \multicolumn{3}{|c|}{$\mathrm{GRR}_{2}=2$} & \multicolumn{3}{|c|}{$\mathrm{GRR}_{2}=3$} \\
\hline \multicolumn{10}{|c|}{ Equal Migration Levels: ${ }_{1} \theta_{2}={ }_{2} \theta_{1}=0.3$} \\
\hline Parameters & $1+2$ & 1 & 2 & $1+2$ & 1 & 2 & $1+2$ & 1 & 2 \\
\hline$r$ & -0.0022 & & & 0.0142 & & & 0.0268 & & \\
\hline $\mathrm{SBR}_{21}$ & 1.00 & & & 2.99 & & & 5.28 & & \\
\hline SHA & 1.0000 & 0.5000 & 0.5000 & 1.0000 & 0.3832 & 0.6168 & 1.0000 & 0.3199 & 0.6801 \\
\hline $\mathrm{b}$ & 0.0131 & 0.0131 & 0.0131 & 0.0232 & 0.0152 & 0.0282 & 0.0331 & 0.0165 & 0.0409 \\
\hline a & 39.08 & 39.08 & 39.08 & 30.80 & 33.96 & 28.84 & $25 \cdot 34$ & 30.17 & 23.06 \\
\hline \multicolumn{10}{|c|}{ Unequal Migration Levels: ${ }_{1} \theta_{2}=0.2 ;{ }_{2} \theta_{1}=0.4$} \\
\hline Parameters & $1+2$ & 1 & 2 & $1+2$ & 1 & 2 & $1+2$ & 1 & 2 \\
\hline $\mathrm{r}$ & -0.0022 & & & 0.0106 & & & 0.0222 & & \\
\hline $\mathrm{SBR}_{21}$ & 0.50 & & & 1.60 & & & 3.01 & & \\
\hline SHA & 1.0000 & 0.6667 & 0.3333 & 1.0000 & 0.5391 & 0.4609 & 1.0000 & 0.4550 & 0.5450 \\
\hline $\mathrm{b}$ & 0.0131 & 0.0131 & 0.0131 & 0.0208 & 0.0148 & 0.0277 & 0.0293 & 0.0161 & 0.0404 \\
\hline a & 39.08 & 39.08 & 39.08 & 32.52 & 35.08 & 29.52 & 27.22 & 31.52 & 23.63 \\
\hline
\end{tabular}

B. High Fertility in Region 1

\begin{tabular}{|c|c|c|c|c|c|c|c|c|c|}
\hline \multicolumn{10}{|c|}{ Fertility Levels: $G_{1}=3$} \\
\hline & \multicolumn{3}{|c|}{$\mathrm{GRR}_{2}=1$} & \multicolumn{3}{|c|}{$\mathrm{GRR}_{2}=2$} & \multicolumn{3}{|c|}{$\mathrm{GRR}_{2}=3$} \\
\hline \multicolumn{10}{|c|}{ Equal Migration Levels: $1_{1}^{\theta_{2}}={ }_{2} \theta_{1}=0.3$} \\
\hline Parameters & $1+2$ & 1 & 2 & $1+2$ & 1 & 2 & $1+2$ & 1 & 2 \\
\hline $\mathrm{r}$ & \multicolumn{3}{|l|}{0.0268} & \multicolumn{3}{|l|}{0.0311} & \multicolumn{3}{|l|}{0.0369} \\
\hline $\mathrm{SBR}_{21}$ & \multicolumn{3}{|l|}{0.19} & \multicolumn{3}{|l|}{0.51} & \multicolumn{3}{|l|}{1.00} \\
\hline SHA & 1.0000 & 0.6801 & 0.3199 & 1.0000 & 0.5884 & 0.4116 & 1.0000 & 0.5000 & 0.5000 \\
\hline b & 0.0331 & 0.0409 & 0.0165 & 0.0368 & 0.0414 & 0.0303 & 0.0419 & 0.0419 & 0.0419 \\
\hline a & 25.34 & 23.06 & 30.17 & 23.68 & 22.49 & 25.40 & 21.70 & 21.70 & 21.70 \\
\hline \multicolumn{10}{|c|}{ Unequal Migration Levels: ${ }_{1} \theta_{2}=0.2 ;{ }_{2} \theta_{1}=0.4$} \\
\hline Parameters & $1+2$ & 1 & 2 & $1+2$ & 1 & 2 & $1+2$ & 1 & 2 \\
\hline $\mathbf{r}$ & \multicolumn{3}{|l|}{0.0306} & \multicolumn{3}{|l|}{0.0332} & \multicolumn{3}{|l|}{0.0369} \\
\hline $\mathrm{SBR}_{21}$ & \multicolumn{3}{|l|}{0.10} & \multicolumn{3}{|l|}{0.26} & \multicolumn{3}{|l|}{0.50} \\
\hline SHA & 1.0000 & 0.7976 & 0.2024 & 1.0000 & 0.7367 & 0.2633 & 1.0000 & 0.6667 & 0.3333 \\
\hline b & 0.0363 & 0.0413 & 0.0167 & 0.0386 & 0.0416 & 0.0305 & 0.0419 & 0.0419 & 0.0419 \\
\hline a & 23.88 & 22.56 & 29.09 & 22.93 & 22.20 & 24.97 & 21.70 & 21.70 & 21.70 \\
\hline
\end{tabular}


and migration. ${ }^{7}$ Each of the 12 populations may be expressed symbolically by any one of the three forms listed earlier. For example, the first stable multiregional population may be expressed as a function of

$$
\underset{\sim}{\operatorname{EXP}}=\left[\begin{array}{cc}
70 & 0 \\
0 & 70
\end{array}\right] \quad r=-0.0022 \quad \operatorname{SBR}=\left[\begin{array}{ll}
1 & 1 \\
1 & 1
\end{array}\right] \quad \underset{\sim}{\theta}=\left[\begin{array}{ll}
7 / 10 & 3 / 10 \\
3 / 10 & 7 / 10
\end{array}\right]
$$

in which $S B R$ could be replaced by

$$
\mathrm{SHA}=\left[\begin{array}{cc}
1 / 2 & 0 \\
0 & 1 / 2
\end{array}\right] \text {. }
$$

Alternatively, the same population may be described as a function of the same $\underset{\sim}{\operatorname{EXP}}$ and $\underset{\sim}{\ominus}$ matrices but with $\mathrm{r}$ and $\underset{\sim}{\mathrm{SBR}}$ (or $\underset{\sim}{\mathrm{SHA}}$ ) replaced by

$$
\mathrm{GRR}_{\sim}=\left[\begin{array}{ll}
1 & 0 \\
0 & 1
\end{array}\right]
$$

7 To develop the fertility matrices $\underset{\sim}{F}(x)$ and the life table matrices $\underset{\sim}{L}(x)$ which are needed as inputs to the calculations, we used Coale and Demeny's basic fertility schedule for $\overline{\mathrm{m}}=29$, their "WEST" model life tables, and our own "AVERAGE" model migration schedules which are set out in another paper (Rogers and Castro, 1975). Given $\underset{\sim}{\mathbb{F}}(\mathrm{x})$ and $\underset{\sim}{L}(\mathrm{x})$ for all $\mathrm{x}$, we evaluate $\underset{\sim}{\Psi}(\mathrm{r})$, deternine the $\mathrm{r}$ that gives it a dominant characteristic root of unity, and solve for the associated characteristic vector $\{Q\}$. 


\subsection{Spatial Impacts of Changes in the Components of Multiregional Population Growth}

Perhaps the simplest way to examine the spatial impacts of particular changes in schedules of fertility, mortality, and migration on an observed population is by means of population projection. Such arithmetical calculations, carried out first with the original and then with the revised schedules, readily identify the effects of the differences between the two growth regimes. However, this approach suffers from a lack of generality and fails to reveal functional relationships that may exist between the changes occasioned in the population studied and its fundamental parameters. Thus mathematical demographers concerned with population dynamics have focused their attention on the behavior of model populations that evolve from different growth regimes (Coale, 1972a; Preston, 1974) or have developed mathematical formulas that trace through the impacts of particular changes in agespecific rates on the population subjected to those rates (Goodman, 1971; Keyfitz, 1971b). Both approaches have adopted the stable population as their basic model and both can be extended to multiregional populations.

Model stable multiregional populations readily reveal the impacts of changes in fertility, mortality, and migration levels. By varying these levels either singly or in various combinations we may establish the long-run consequences of particular changes in the components of population growth and, in the process, obtain an improved understanding of the population dynamics that are involved. For example, consider some of the more interesting aspects of population dynamics that are revealed by the stable populations presented in Table 3.2 (and illustrated in Figures $2.4 \mathrm{~B}$ and $2.4 \mathrm{C}$ ). First, an unchanging multiregional growth regime in which regional fertility and mortality levels are identical produces identical stable regional age compositions, even though their stable regional shares vary inversely with the ratio of their migration levels, i.e., $\frac{\operatorname{SHA}_{j}}{\operatorname{SHA}_{i}}=\frac{i_{j}}{\theta_{i}}$. 
second, as in the single-region model, higher values of the intrinsic rate of growth create stable (regional) populations that taper more rapidly with age and, in consequence, include a higher proportion of the population below every age Further, fertility not only affects the rate of growth of a stable population but, in the multiregional case, it also affects the stable regional allocations of such populations. Mortality and migration schedules also affect the form of the stable regional age compositions and the stable regional shares in an obvious way, and any idiosyncracies in the age patterns of such schedules will be reflected in the stable regional populations.

A rather surprising $f$ inding is the relative insensitivity of the regional age compositions and birth rates to migration levels. Consider, for example, the case of unequal migration 1 evels with $\mathrm{GRR}_{1}=1, \mathrm{GRR}_{2}=3$ and $\mathrm{GRR}_{1}=3, \mathrm{GRR}_{2}=1$, respectively. In the first instance the region with the larger (by a factor of 2) outmigration has the higher fertility level; in the second case the situation is reversed. Yet in both instances the population in the region with the higher fertility level has an average age of approximately 23 years and exhibits a birth rate of approximately 41 per 1000. This insensitivity to migration behavior does not extend to systemwide measures, however. For example, the intrinsic growth rate and systemwide birth rate are considerably lower in the first case than in the second, and the higher fertility region assumes a stable region share of only 54 percent in the first case but receives 80 percent in the second.

The confounding of regional differentials in mortality with those of fertility and migration produces complex interactions that generate even more complex patterns of growth and change.

For example, in a two-region population system with fixed, identical regional schedules of fertility and migration, the regional population with the highcr expectation of life at birth (i.e., with the lower mortality level) ultimately 
assumes the higher stable regional share of the total multiregional population and becomes the older population with the lower birth rate. As fertility in the region with the higher life expectancy is increased relative to that in the other region, the high fertility population assumes an even higher stable regional share and develops into the younger population with the higher birth rate. However, if the increase in relative fertility occurs instead in the region with the lower life expectancy, this pattern may be reversed and the regional population with the higher mortality level can become the population with the higher stable regional share, the lower average age, and the higher birth rate.

We have considered some of the spatial impacts of changes in the components of population growth by examining model stable multiregional populations. We could instead have directed our efforts toward a mathematical analysis of the impacts on the stable population of changes in rates at a particular age in the manner of Keyfitz (1971b) say. The details of such an approach will be developed in a forthcoming paper and we, therefore, only sketch out the principal arguments here. Our approach follows Keyfitz's chain of derivations and centers on the multiregional generalization of his principal formulas.

Keyfitz begins his derivations by tracing through the effect on $p(a)$, the probabjlity of surviving from birth to age $a$, of a change $4(x)$ in the age-specific death rate $\mu(x)$ applied to ages $x$ to $x+\Delta x$, where $a>x+\Delta x$. He shows that the change $\Delta p(a)$ occasioned by the change $\Delta \mu(x)$ may be found by

$$
\Delta p(a) \doteqdot-p(a) \Delta w(x) \Delta x, a>x+\Delta x,
$$

and concludes that the effect of a change in the age-specific death rate $\mu(x)$ on the expectation of 1 ife at age a is approximated by

$$
\Delta e(a) \doteqdot-\frac{p(x)}{p(a)} e(x) A_{\mu}(x) \text {. }
$$


Keyfitz then goes on to identify the effects of changes in age-specific birth and death rates on stable population parameters such as the intrinsic rate of growth, the intrinsic birth and death rates, and the age composition and mean age of the stable population.

The multiregional generalizations of (3.11) and (3.12) may be shown to be, respectively,

$$
\Delta \underset{\sim}{P}(\mathrm{a}) \doteqdot \Delta \underset{\sim}{V}(\mathrm{x}) \Delta \mathrm{x}_{\sim}^{\mathrm{P}}(\mathrm{a}) \quad \mathrm{a}>\mathrm{x}+\Delta \mathrm{x}
$$

and

$$
\underset{\sim}{\operatorname{es}}(\mathrm{a}) \doteqdot \underset{\sim}{\Delta}(\mathrm{x}) \underset{\sim}{e}(\mathrm{x}) \underset{\sim}{\mathrm{P}}(\mathrm{x}) \underset{\sim}{\mathrm{P}}(\mathrm{a})^{-1}
$$

where, for example, in a two-region population system

$$
v(x)=\left[\begin{array}{cc}
-\left(\mu_{i}(x)+\nu_{i j}(x)\right) & v_{j i}(x) \\
v_{i j}(x) & -\left(\mu_{j}(x)+v_{j i}(x)\right)
\end{array}\right],
$$

in which $u_{i}(x)$ and $v_{i j}(x)$ denote instantaneous rates of mortality and migration, respectively. 


\section{The Spatial Dynamics of Stationary Populations}

Increasing fublic concern about the sizes and growth rates of national populations has generated a vast literature on the social, economic, and environmental impacts of a reduction of fertility to replacement levels and the consequent evolution of national populations to a zero growth condition (e.g., Coale, 1972b, Frejka, 1973). But where people choose to live in the future presents issues and problems that are potentially as serious as those posed by the number of children they choose to have. Yet the spatial implications of reduced fertility have received very little attention and we are, in consequence, ill-cquipped to develop an adequate response to questions such as the one recently posed by the Commission on Population Growth and the American Future: 1

$$
\begin{aligned}
& \text { "How would stabilization of the national population affect } \\
& \text { migration and local growth"? (C.P.G.A.F., 1972, p. 13) }
\end{aligned}
$$

The Commission observes that zero growth for the nation will mean an average of zero growth for local areas. This, of course, still allows for the possibility of nonzero growth in particular localities. Thus spatial zero growth, like temporal zero growth, may be viewed either as a condition that ultimately prevails uniformly or one that exists only because of a fortuitous balancing of regional rates of positive growth, of zero growth, and of decline. Since no obvious advantages

\footnotetext{
$\overline{I_{A} \text { notable exception is the work of Peter Morrison, who concludes: "...denographic }}$ processes interact in subtle and often complex ways, and the mechanisms by which declining fertility would influence population redistribution are only partially understood. Their elucidation can furnish a clearer picture of how and under what circumstances population redistribution can be influenced by public policy," (Morrison, 1972, p. 547).
} 
arise from the latter case, demographers quite naturally have viewed the attainment of temporal zero growth in the long-run in terms of an indefinite continuation of temporal zero growth in the short-run. We follow this tradition in this paper and view the attainment of spatial zero growth in the long-run in terms of temporal zero growth within each region of a closed multiregional population system. In consequence, we confine our attention here to the evolution of stationary multiregional populations, i.e., stable multiregional populations that have a zero growth rate. Thus we augment the usual twin assumptions of a fixed mortality schedule and a fixed fertility schedule set at replacement level with the assumption of a fixed migration schedule. Multiregional populations subjected to such regional growth regimes ultimately assume a persisting zero rate of growth in every region and exhibit zero growth both over time and over space. 


\subsection{Characteristics of Stationary Multiregional Populations}

If age-specific death rates remain unchanged and the annual number of births is fixed, a population that is closed to migration will ultimately evolve into a stationary population. The characteristics of such a population are well known. The number of individuals at any age would remain fixed, and the total number of deaths would exactly equal the total number of births. Because mortality risks would be relatively low from just after birth through middle age, the age composition of such a population would be nearly rectangular until ages 50 or 60 , tapering much more rapidly thereafter as death rates increase among the older population.

The maintenance of a stationary population requires that parents have only as many children as are needed to maintain a fixed number of births every year. This means, for example, that a 1000 women must on the average produce a 1000 baby girls during their lifetime. Moreover, since some women will not survive to become mothers, those who do must have slightly more than 1000 daughters in order to compensate for those who don't. Hence the gross reproduction rate must be greater than unity by an amount just sufficient to maintain a unit level of net reproduction. For example, about 97 to 98 percent of women in the United States today survive to the principal ages of childbearing. Consequently, those who do must have approximately 1.027 daughters, on the average, as they pass through the childbearing ages. In other words, the GRR must be 1.027 in order for the NRR to be unity. ${ }^{2}$

2

2 Because there are usually about 105 baby boys born for every 100 baby girls, mothers in a stationary population of males and females would need to have a total rate of reproduction about 3 percent more than twice 1.027 . In this way we obtain the total fertility rate of 2.11 used, for example, in the United States Census Bureau projections, (U.S. Bureau of the Census, 1972). 
The net reproduction rate, like the total fertility rate and the gross reproduction rate, summarizes the fertility experience of a population of all ages during a single year as if it were the experience of a single cohort that passed through all ages. It is a hypothetical value that treats crosssectional data as if it were longitudinal data in order to estimate the number of daughters that would be born per woman subjected to specified age-specific risks of fertility and mortality. A commonly used procedure for obtaining NRR is to multiply each female age-specific fertility rate by the corresponding probability of surviving from birth to that age and integrate the product over all ages of childbearing:

$$
\mathrm{NRR}=\int_{\alpha}^{\beta} \mathrm{p}(\mathrm{x}) \mathrm{m}(\mathrm{x}) \mathrm{dx} \equiv \mathrm{R}(0) \text {. }
$$

Since NRR may be viewed as the zero ${ }^{\text {th }}$ moment of the net maternity function, it usually is denoted by $R(0)$, a notation which we shall adopt henceforth.

Total births in a stationary multiregional population must, of course, also equal total deaths. However, because of the redistributive effects of migration, total births in any particular region need not equal total deaths in that region. This can be readily demonstrated by means of the accounting identity connecting regional stable intrinsic rates:

$$
r=b_{j}-d_{j}-o_{j}+i_{j}=b_{j}-d_{j}+n_{j},
$$

which with $r=0$ defines the fundamental relationship that must hold in every region of a stationary multiregional population:

$$
\hat{\mathrm{b}}_{j}+\hat{\mathrm{n}}_{j}=\hat{\mathrm{d}}_{j}
$$

where the caret is introduced to designate a stationary population. Thus only if the net migration rate is zero will regional births equal regional deaths. 
The maintenance of a stationary multiregional population requires that the total number of births in every region remain constant over time. Thus we may substitute the trial solution vector $\{\mathrm{B}(t)\}=\{\hat{\Omega}\}$ into (3.1) to find

$$
\{\hat{Q}\}=\left\{\int_{\alpha}^{\beta} \stackrel{M}{M}(x) \underset{\sim}{P}(x) d x\right\}\{\hat{Q}\}=\hat{R}(0)\{\hat{Q}\} \text {, }
$$

where carets are once again used to distinguish stationary population measures, and the element in the $i^{\text {th }}$ row and the $j^{\text {th }}$ colum of $\underset{\sim}{\mathrm{R}}(0)$ is the stationary regional net reproduction rate in regiou $i$ of women born in regicn $j$ :

$$
\hat{\mathrm{R}}_{i}(0)=\int_{\alpha}^{\beta} \mathrm{j}_{i}(x) \hat{\mathrm{n}}_{i}(x) d x
$$

Equation (4.2) shows that for a stationary multiregional population to be maintained, the dominant characteristic root of the matrix $\underset{\sim}{\mathrm{R}}(0)$ must be unity. Consequently a reduction of fertility to replacement level may be interpreted as a reduction of the elements of $\underset{\sim}{M}(x)$ to a level that reduces the dominant characteristic root of a given net reproduction matrix $\underset{\sim}{R}(0)$ to unity. Such an operation transforms $\underset{\sim}{M}(x)$ to $\underset{\sim}{M}(x)$ and $\underset{\sim}{R}(0)$ to $\underset{\sim}{R}(0)$.

Stabilization of the regional populations in a multiregional population will alter the relative contributions of natural increase and migration to regional growth. Regional age compositions will aiso be affected, and in ways that are strongly influenced by the age patterns of migration. Retirement havens such as San Diego and Miami, for example, will receive proportionately higher flows of inmigrants as the national population increases in average age, whereas destinations that previously attracted mostly younger migrants will receive proportionately fewer inmigrants. Finally, as we demonstrate in the next section, the redistributional effects of stabilization depend in a very direct way on the redistribution of total births that is occasioned by the reduction in fertility. 


\subsection{Alternative Spatial Paths to a Stationary Multiregional Population}

In his paper for the Commission on Population Growth and the American Future, Ansley Coale (1972b) considers three alternative paths to a stationary population: (1) maintaining births constant at the levels recorded in 1970; (2) moving to a replacement level of fertility either immediately or in the very near future; and (3) reducing childbearing levels such that total population size is held fixed beginning immediately. He finds only slight differences between the first two alternatives and rejects the third as infeasible since it would require an immediate decline in the birth rate of almost 50 percent. We shall therefore confine our attention to Coale's second alternative path and will explore a few of its spatial ramifications.

Imagine a multiregional population system growing at some positive rate of growth, i.e., exhibiting a net reproduction matrix $\underset{\sim}{R}(0)$ with a dominant characteristic root $\lambda_{1}(\mathrm{R}(0))$ greater than unity. If the rate of childbearing in each region of this multiregional population system were immediately reduced such that every woman born in that region would have a net reproduction rate of unity, then

$$
\hat{i}(0)=\sum_{j=1}^{m} \hat{R}_{j}(0)=1
$$

or, in matrix form,

$$
\hat{\mathrm{R}}(0) \cdot\{\underset{\sim}{\sim}\}=\{1\}
$$

where the prime denotes transposition.

As in the normal practice in single-region exercises of this $k$ ind, assume that the reduction of the fertility of each regional cohort of women is achieved by reducing that cohort's age-specific fertility rates by the same fixed proportion, $v_{i}$ say. Then

$$
\hat{i}(0)=\sum_{j=1}^{m} \hat{R_{j}}(0)=\sum_{j=1}^{m} \int_{\alpha}^{\beta}{ }_{i} P_{j}(x) \gamma_{j} m_{j}(x) d x=\sum_{j=1}^{m} \gamma_{j} R_{j}(0)=1
$$


and

$$
\hat{R}(0)=\underset{\sim}{\underline{R}}(0) \text {, }
$$

where $\underline{Y}$ is a diagonal matrix of fertility adjustment factors. Substituting (4.4) into (4.3) gives

$$
\stackrel{\sim}{R}(0)^{\prime} \not{\sim}\{\underset{\sim}{1}\}=\{\underset{\sim}{\dot{1}}\}
$$

whence

$$
\{y\}=\left[\underset{\sim}{R}(0)^{\prime}\right]^{-1}\left\{\frac{1}{\{}\right\}
$$

The adjusitment factor $\gamma_{i}$ may be re-expressed in a way that offers additional insights into its properties. According to (4.2)

$$
\hat{Q}_{i}=\sum_{j=1}^{m} \hat{R}_{i}(0) \hat{Q}_{j}
$$

Dividing both sides of the equation by $\hat{Q}_{i}$ gives

$$
1=\sum_{j=1}^{m} \frac{\hat{Q}_{j}}{\hat{Q}_{i}} \hat{R}_{i}(0)=\hat{R}_{i}(0) \text {, say, }
$$

where $\hat{R}_{i}(0)$ may be defined to be the net reproduction of women living in region $i$ (as distinguished from the net reproduction of those born in region i). But

$$
\hat{R}_{i}(0)=\sum_{j=1}^{m} \frac{\hat{Q}_{j}}{\hat{Q}_{i}} \gamma_{i j} R_{i}(0)=\gamma_{i} R_{i}(0)=1 \text {, }
$$

where we define $R_{i}(0)=\sum_{j=1}^{m} \frac{\hat{Q}_{j}}{\hat{Q}_{i}}{ }^{R}{ }_{i}(0)$. Hence

$$
\gamma_{i}=\frac{1}{R_{i}(0)}
$$

and

$$
\{\underset{\sim}{R}(0)\}=\sim_{\sim}^{-1}\{\underset{\sim}{1}\}=\hat{Q}^{-1} \underset{\sim}{R}(0)\{\hat{Q}\},
$$

where $\{\hat{\beta}\}=\hat{g}\left\{\begin{array}{l}1 \\ \sim\end{array}\right.$. 
The vector $\{\hat{Q}\}$ in $(4.6)$ is the characteristic vector associated with the unit dominant characteristic root of $\underset{\sim}{\hat{R}}(0)$ and denotes the total number of births in each region of a stationary multiregional population. The proportional allocation of total births that it defines is directly dependent on the transformation that is applied to change $\underset{\sim}{\mathrm{R}}(0)$ to $\underset{\sim}{\mathrm{R}}(0)$, a particular example of which is given by (4.4). Since in a stationary multiregional population the regional stationary equivalent population $\hat{Y}_{i}$ is equal to the quotient $\hat{Q}_{i} / \hat{b}_{i}$, we see that the different ways in which $\underset{\sim}{R}(0)$ is transformed into $\underset{\sim}{\mathrm{R}}(0)$ become, in fact, alternative "spatial paths" to a stationary multiregional population.

A numerical example may be instructive at this point. The net reproduction behavior of the urban and rural female populations of the United States in 1968 is crudely approximated by the net reproduction matrix

$$
\underset{\sim}{R}(0)=\left[\begin{array}{ll}
u^{R} u^{(0)} & r^{R}(0) \\
u^{R}(0) & r_{r}^{R}(0)
\end{array}\right]=\left[\begin{array}{ll}
0.85 & 0.45 \\
0.25 & 0.90
\end{array}\right],
$$

where, for example, $r_{u}(0)=0.45$ denotes the net reproduction rate in urban areas of rural-born women. In other words, under the regime of growth observed in 1968, each woman born in rural areas wi11, on the average, replace herself in the succeeding generation by 1.35 daughters, one third of whom will be born in urban areas. Urban-born women, on the other hand, have a lower net reproduction rate, i.e., ${ }_{u} R(0)=1.10<{ }_{r} R(0)$, which when combined with the net reproduction rate of rural-born women gives the United States female population an overall net reproduction rate of $\left.\lambda_{1} \underset{\sim}{(R}(0)\right)=1.21$, where $\lambda_{1} \underset{\sim}{(R(0))}$ is the dominant characteristic root of the net reproduction matrix $\underset{\sim}{R}(0)$.

About 73 percent of the 1968 United States female population lived in urban areas. A projection to stable growth under the 1968 growth regime reduces that allocation to approximately $2 / 3$ of the stable population and yields an intrinsic 
growth rate of slightly under one percent per annum. What would be the spatial allocation under a similar projection, but one in which fertility was immediately reduced to a level of one daughter per urban-or rural-born woman? To obtain an estimate of the regional shares in the stationary population that would evolve out of such a projection we need to first derive the fertility adjustment factors $\gamma_{u}$ and $Y_{\mathbf{r}}$, respectively. Calculations carried out using (4.5) give $\gamma_{u}=1$ and $\gamma_{\mathrm{r}}=3 / 5$, whence

$$
\underset{\mathrm{R}}{\hat{\mathrm{N}}}(0)=\left[\begin{array}{ll}
0.85 & 0.45 \\
0.15 & 0.55
\end{array}\right]
$$

Note that both groups of women now exhibit unit rates of net reproduction, and observe that the dominant characteristic root of $\underset{\sim}{\hat{R}}(0)$ is unity.

The characteristic vector associated with the unit dominant characteristic root of $\hat{\mathrm{R}}(0)$ indicates that $3 / 4$ of the total births in the stationary multiregional population will occur in urban areas. Since $\hat{Q}_{i}=\hat{b}_{i} \hat{Y}_{i}$,

$$
\frac{\hat{Y}_{i}}{\hat{Y}_{j}}=\frac{\hat{Q}_{i}}{\hat{Q}_{j}} \cdot \frac{\hat{b}_{j}}{\hat{b}_{i}} \text {, }
$$

a result that equates the ratio of stationary regional shares to the corresponding stationary birth ratio times the reciprocal of the corresponding ratio of intrinsic birth rates. Since the stationary birth ratio of urban to rural births is given by $\hat{\mathrm{R}}(0)$ to be 3 (i.e., $3 / 4$ to $1 / 4$ ) and because the ratio of rural to urban intrinsic birth rates is likely to be close to unity (it comes out to be 1.07 in the projection) we conclude that in the stationary multiregional population about $3 / 4$ of the population would reside in urban areas. ${ }^{3}$

\footnotetext{
3 This result of course refers to regional designations that existed in 1968 . In light of the continuing urbanization of rural regions it is probably a conservative estimate.
} 
We have observed earlier that the praportional allocation of total births in a stationary multiregional population deperds directly on the transformation by which $\underset{\sim}{\mathrm{R}}(0)$ is changed to $\underset{\mathrm{R}}{\mathrm{R}}(0)$. Alternative transformations are in effect alternative spatial paths to such a population inasmuch as they lead to alternative spatial allocations of the total nultiregional population. This can be easily illustrated by considering an alternative fertility reduction program which reduces the aggregate net reproduction rate to unity by reducing each regional fertility schedule by the same proportion, $\gamma$ say. That is,

$$
\begin{aligned}
& \underset{\sim}{\hat{\mathrm{R}}}(0)=\underset{\sim}{R}(0), \text { where } \\
& Y=\frac{1}{\lambda_{1}(\mathrm{R}(0))} .
\end{aligned}
$$

In the context of our numerical illustration this means that the fertility of urban-born women would now be reduced to below replacement levels whereas that of rural-born women would be permitted to exceed replacement fertility levels. That is,

and $\hat{\mathrm{u}}(0)=0.91, \quad \hat{\mathrm{r}}(0)=1.11$.

$$
\underset{\sim}{\hat{R}}(0)=\frac{1}{1.211} \underset{\sim}{R}(0)=\left[\begin{array}{ll}
0.70 & 0.37 \\
0.21 & 0.74
\end{array}\right] \text {, }
$$

The spatial implications of this alternative path to a stationary multiregional population are quite different, as can be seen by calculating the characteristic vector associated with the unit dominant characteristic root of $\hat{\hat{R}}(0)$. The characteristic vector in this case allocates approximately 35 percent of total multiregional births to urban areas. Since the ratio of rural to urban intrinsic birth rates would now be sonewhat higher than unity, however, we should expect a correspondingly higher concentration in urban areas than is indicated by this allocation of total births. 


\subsection{On the Momentum of Multiregional Population Growth}

Differences between most observed population age compositions and those of stationary populations make it virtually impossible to attain zero growth in the near future. A population's birth rate and growth rate depend on its fertility schedule and its age composition. Consequently whether and how long a population continues to grow after achieving a net reproduction rate of unity depends on that populations's age composition and its degree of divergence from that of a stationary population. The ratio by which the ultimate stationary population exceeds a current population is the "momentum" of that population, a quantity that recently has begn given analytical content by Keyfitz (1971a) who shows that the momentum of a population numbering $\mathrm{K}$ individuals and having an age composition close to stable may be approximated by the expression

$$
\frac{\hat{Y}}{\mathrm{~K}}=\frac{\mathrm{b} e(0)}{\mathrm{r} \mu}\left(\frac{\mathrm{R}(0)-1}{\mathrm{R}(0)}\right) \text {, }
$$

where $b$ is the birth rate, $r$ the rate of growth, e(0) the expectation of life, and $R(0)$ the net reproduction rate, all measured before the drop in fertility, - and $\mu$ is the mean age of childbearing afterward. The derivation assumes that the the population is approximately stable before the decline in fertility so that $b$ and $r$ are intrinsic stable rates of the initial (nonstationary) regime of growth. Straightforward population projection calculations may be used to obtain the future population that evolves from any particular observed or hypothetical regime of growth. Therefore (4.11) is not needed to obtain a numerical estimate of an ultimate stationary population. However Keyfitz's simple momentum formula gives us an understanding of the population dynamics that are hidden in the arithmetical computations of a population projection. It identifies in an unambiguous way the five parameters of a current population that determine the size of the ultimate stationary population. 
In order to evaluate the accuracy of Keyfitz's momentum fo:mula we have carried out a two-region projection of the 1968 United states female population on the assumpution that age-specific fertility rates in each region drop immediately to replacement levels. Table 4.1 shows that the ultimate total stationary multiregional population exceeds its 1968 level by about a third. Equation (4.11) estimates the momentum to be about the same: ${ }^{4}$

$$
\frac{\hat{Y}}{\mathrm{~K}(1968)^{\circ}}=\frac{0.01878}{0.00432} \cdot \frac{74.3}{26.3} \frac{(1.12-1)}{1.12}=1.31 \text {. }
$$

A multiregional generalization of Keyfitz's momentum formula may be show to be

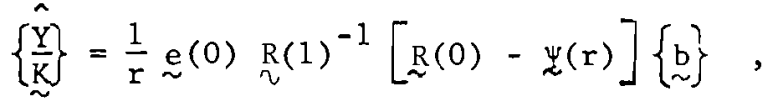

where $R_{(1)}(1)$ is a matrix with elements ${ }_{j}{ }^{R}(1)={ }_{j} \mu_{i}{ }_{j}{ }^{R}{ }_{i}(0)$, and where tota.

multiregional stable births $Q$ are allocated to regions according to the stationary proportions defined by the characteristic vector associated with the unit dominant characteristic root of $\underset{\sim}{\mathrm{R}}(0)$. Evaluating (4.12) with the same two-region data that produced the results in Tables 3.1 and 4.1 gives:

$$
\begin{aligned}
& {\left[\begin{array}{c}
\frac{\hat{Y}_{i}}{K_{i}(1968)} \\
\frac{\hat{Y}_{j}}{K_{j}(1968)}
\end{array}\right]=\frac{1}{0.00432}\left[\begin{array}{ll}
52.39 & 6.95 \\
23.10 & 67.34
\end{array}\right]\left[\begin{array}{rr}
0.0509 & -0.0045 \\
-0.0161 & 0.0382
\end{array}\right]\left[\begin{array}{ll}
0.0833 & 0.0098 \\
0.0350 & 0.1108
\end{array}\right] x} \\
& \mathrm{x}\left[\begin{array}{l}
0.02377 \\
0.01777
\end{array}\right]=\left[\begin{array}{l}
1.74 \\
1.23
\end{array}\right]
\end{aligned}
$$

\footnotetext{
$\overline{4}$ Unlike Keyfitz we do not use the observed birth rate but divide total stable biiths $\mathrm{Q}$ by the current population, i.e., $\mathrm{b}=\mathrm{Q} / \mathrm{K}(1968)=1,920,961 / 102,276,992=0.01878$. That is why our approximation is more accurate than similar ones reported by Keyfitz.
} 
TABLE 4.1 - RELATIONS UNDER STATIONARITY: FEMALE POPULATION OF THE UNITED STATES, 1968

\begin{tabular}{|c|c|c|c|c|c|}
\hline \multirow{2}{*}{ Age, $x$} & \multicolumn{2}{|c|}{ 1. The West Region } & \multicolumn{3}{|c|}{ 2. The Rest of the United States } \\
\hline & $\begin{array}{lc}\text { Stationary } & \text { Equivalent } \\
1+2 & 1\end{array}$ & $\begin{array}{c}\text { Population } \\
2\end{array}$ & $1+2$ & $\begin{array}{c}\text { Proportion } \\
1\end{array}$ & 2 \\
\hline 0 & $8,919,063$ & $6,919,777$ & 0.0662 & 0.0645 & 0.0668 \\
\hline 5 & $8,801,161$ & $6,840,480$ & 0.0654 & 0.0632 & 0.0660 \\
\hline 10 & $8,786,342$ & $6,831,451$ & 0.0653 & 0.0630 & 0.0659 \\
\hline 15 & $8,767,142$ & $6,793,946$ & 0.0651 & 0.0636 & 0.0656 \\
\hline 20 & $8,739,604$ & $6,745,615$ & 0.0649 & 0.0643 & 0.0651 \\
\hline 25 & $8,706,948$ & $6,719,827$ & 0.0647 & 0.0641 & 0.0648 \\
\hline 30 & $8,663,633$ & $6,695,537$ & 0.0643 & 0.0635 & 0.0646 \\
\hline 35 & $8,596,752$ & $6,648,156$ & 0.0638 & 0.0628 & 0.0642 \\
\hline 40 & $8,493,131$ & $6,568,144$ & 0.0631 & 0.0621 & 0.0634 \\
\hline 45 & $8,341,530$ & $6,447,014$ & 0.0620 & 0.0611 & 0.0622 \\
\hline 50 & $8,126,033$ & $6,272,832$ & 0.0604 & 0.0598 & 0.0605 \\
\hline 55 & $7,822,168$ & $6,028,684$ & 0.0581 & 0.0578 & 0.0582 \\
\hline 60 & $7,401,017$ & $5,689,697$ & 0.0550 & 0.0552 & 0.0549 \\
\hline 65 & $6,805,483$ & $5,210,627$ & 0.0505 & 0.0514 & 0.0503 \\
\hline 70 & $5,963,701$ & $4,538,576$ & 0.0443 & 0.0460 & 0.0438 \\
\hline 75 & $4,814,365$ & $3,632,267$ & 0.0358 & 0.0381 & 0.0351 \\
\hline 80 & $3,410,328$ & $2,543,945$ & 0.0253 & 0.0279 & 0.0245 \\
\hline $85+$ & $3,480,965$ & $2,498,794$ & 0.0259 & 0.0317 & 0.0241 \\
\hline Total & $134,639,366 \quad 31,013,997$ & $103,625,370$ & 1.0000 & 0.2303 & 0.7697 \\
\hline & $\begin{array}{l}\text { STATIONARY POPUL } \\
\mathrm{r} \text { - Rate of growth } \\
\hat{\mathrm{Y}} \text { - Stationary equivale } \\
\hat{\mathrm{SHA}}=\hat{\mathrm{Y}} / \mathrm{\Sigma} \hat{\mathrm{Y}} \text { - Stationary } \mathrm{r} \\
\hat{\mathrm{Q}}-\text { Stationary equivale } \\
\hat{\mathrm{SBR}} \hat{\mathrm{Q}}_{2} / \hat{\mathrm{Q}}_{1} \text { - Stationar } \\
\hat{\mathrm{b}}-\text { Birth rate } \\
\hat{\mathrm{d}}-\text { Death rate } \\
\hat{\mathrm{o}}-\text { Outmigration rate } \\
\hat{\mathrm{i}}-\text { Inmigration rate } \\
\hat{\mathrm{n}}-\text { Net migration rate } \\
\hat{\mathrm{a}}-\text { Mean age }\end{array}$ & $\begin{array}{l}\text { TION: } \\
\text { population } \\
\text { gional share } \\
\text { t births } \\
\text { birth ratio }\end{array}$ & $\begin{array}{c}0.00000 \\
134,639,366 \\
1.0000 \\
1,805,735 \\
3.44 \\
0.0134 \\
0.0134 \\
-- \\
-- \\
-- \\
39.65\end{array}$ & $\begin{array}{c}31,013,997 \\
0.2303 \\
406,374 \\
0.0131 \\
0.0133 \\
0.0079 \\
0.0080 \\
0.0002 \\
40.45\end{array}$ & $\begin{array}{l}0.0135 \\
0.0135 \\
0.0024 \\
0.0024 \\
-0.0000 \\
39.41\end{array}$ \\
\hline
\end{tabular}


A comparison of these regional momenta with those found by population projection and set out in Table 4.1 reveals that the quality of approximation afforded by (4.12) is adequate ( 1.74 and 1.23 as approximations of 1.80 and 1.22 , respectively). Equation (4.12) is not as practically useful as its single-region counterpart because it is much more difficult to come up with accurate guesses or estimates of the values taken on by the many parameters. Thus a more effective procedure may be to first estimate the ultimate size of the total stationary multiregional population using Keyfitz's formula and then rely on (4.8) to allocate that total to the various regions of the multiregional system. Such a procedure requires estimates of the stationary birth rate ratios. 


\section{Conclusion}

It is an unassailable fact of life that current rates of population growth cannot prevail for a very long period of time in the future. Coale (1972b) for example, points out that were the United States population to contirue to increase at its present rate of about one percent a year, there would be more than one American per square foot of land in less than 1300 years. In an analogous vein, Keyfitz (1971c) observes that Mexico cannot continue with its current rate of growth for as long as the lifetimes of children now born, for if it did its population would increase sixteen-fold to about 800 million people in that span of time. Of what use then are population projections developed on the basis of constant rates?

Knowledgeable users of population projections know full well that the assumptions that generated them are certain to be violated. This is especially true of multiregional projections that assume fixed schedules of internal migration. Unlike fertility or mortality, migration is functionally related to two populations instead of one. Thus it is patently unrealistic to assume that age-specific rates of migration between two regional populations will remain unaffected by changes in the relative sizes of these populations over time. Nonlinear models of growth therefore deserve an important place in any agenda of demographic research. Nevertheless, the knowledgeable user of demographic models will still find that linear multiregional models of population growth can indeed provide a better understanding of the spatial dynamics of such growth. They

"permit experiments out of which we obtain causal knowledge; they explain data; they focus research by identifying theoretical and practical issues; they systematize comparative study across space and time; they reveal formal analogies between problems that on the surface are quite different; they even help assemble data," (Keyfitz, 1971c, p. 573). 


\section{REFERENCES}

Coale A.J. (1972a). The Growth and Structure of IJuman Populations. (Princeton, N.J.: Princeton University Press).

(1972b). "Alternative Paths to a Stationary Population," in Demographic and Social Aspects of Population Growth, Ed., C.F. Westoff and R. Parke, Jr., U.S. Commission on Population Growth and the American Future (Washington, D.C.: U.S. Government Printing Office), Pp. 589-603.

and P. Demeny (1966). Ragional Model Life Tables and Stable Populations (Princeton, N.J.: Princeton University Press).

Commission on Population Growth and the American Future (1972). Population and the American Future. (Washington, D.C.: U.S. Government Printing Office).

Frejka, T. (1973). The Future of Population Growth: Alternative Paths to Equilibrium (New York: John Wiley).

Gale, D. (1967). "On Optimal. Development in a Multi-Sector Economy," Review of Economic Studies, XXXIV, 1-18.

Goodman, L. (1971). "On the Sensitivity of the Intrinsic Growth Rate to Changes in Age-Specific Birth and Death Rates," Theoretical Population Biology, II, $339-354$.

Keyfitz, N. (1968). Introduction to the Mathematics of Population, (Reading, Mass.: Addison-Wesley).

(1969). "Age Distribution and the Stable Equivalent," Demography, VI, 261-269.

(1971a). "On the Momentum of Population Growth," Demograpriy, VIII:1, $71-80$

(1971b). "Linkages of Intrinsic to Age-Specific Rates," Journal of the American Statistical Association, LXVI:334, 275-281.

(1971c). "Models," Demography, VIII:4, 571-580.

(1972). "On Future Population," Journal of the American Statistical Association, J.XVII: $338,347-363$.

and W. Flieger (19\%1). Pupulation: Facts and Methods of Demography (San Francisco, Cal.: Freeman).

Long, L.H. (1973). "New Estimates of Migration Expectancy in the United States," Journal of the American Statistical Association, LXVIII, 37-43.

Lopez, A. (1961). Problems in Stable Population Thoory (Princeton, N.J.: Office of Population Research, Princeton University). 
Lowry, I.S. (1966). Migration and Metropolitan Growth: Two Analytical Models. (San Francisco, Cal.: Chandler).

Morrison, P.A. (1972). "The Impact of Population Stabilization on Migration and Redistribution," in Population, Distribution, and Policy, Ed., S.M. Mazie, U.S. Commission on Population Growth and the American Future (Washington, D.C.: U.S. Government Printing Office), pp. 543-560.

Preston, S.H. (1974). "Effect of Mortality Change on Stable Population Parameters," Demography, XI:1, 119-130.

Rele, J.R. (1967). Fertility Analysis Through Extension of Stable Population Concepts. (Berkeley, Calif.: Institute of International Studies, Univ. of California).

Rogers, A. (1971). Matrix Methods in Urban and Regional Analysis, (San Francisco, Calif.: Holden-Day).

(1975). Introduction to Multiregional Mathematical Demography

(New York: John Wiley).

and L. Castro (1975). "Model Multiregional Life Tables and Stable Populations," forthcoming.

U.S. Bureau of the Census, (1972). "Illustrative Population Projections for the United States: The Demographic Effects of Alternative Paths to Zero Growt Census Population Reports, Series P-25, No. 480 (Washington, D.C.: U.S. Government Printing Office). 